\title{
Financial literacy, financial advice, and financial behavior
}

\author{
Oscar A. Stolper ${ }^{1} \cdot$ Andreas Walter $^{2}$
}

(C) The Author(s) 2017. This article is published with open access at Springerlink.com

\begin{abstract}
In this survey, we review the voluminous body of literature on the measurement and the determinants of financial literacy. Wherever possible, we supplement existing findings with recent descriptive evidence of German households' financial literacy levels based on the novel Panel on Household Finances dataset, a large-scale survey administered by the Deutsche Bundesbank and representative of the financial situation of households in Germany. Prior research not only documents generally low levels of financial literacy but also finds large heterogeneity in financial literacy across the population, suggesting that economically vulnerable groups are placed at further disadvantage by their lack of financial knowledge. In addition, we assess the literature evaluating financial education as a means to improve financial literacy and financial behavior. Our survey suggests that the evidence with respect to the effectiveness of the programs is rather disappointing. We also review the role of individuals' financial literacy for the use of professional financial advice and assess whether expert intervention can serve as a substitute to financial literacy. We conclude by discussing several directions for future research.
\end{abstract}

Keywords Financial literacy · Financial education · Household finance - Financial advice $\cdot$ Financial behavior

JEL Classification A20 - D14 - G11 - I20 - J26

Andreas Walter

Andreas.Walter@wirtschaft.uni-giessen.de

Oscar A. Stolper

oscar.stolper@wiwi.uni-marburg.de

1 Philipps-Universität Marburg, Am Plan 1, 35032 Marburg, Germany

2 Justus-Liebig-Universität Gießen, Licher Straße 74, 35394 Gießen, Germany 


\section{Introduction}

In recent years, consumers across the globe have taken on greater responsibility with regards to their personal financial well-being. Sweeping changes in the pension landscape have marked the principal catalyst for this increased autonomy of consumers by passing financial decisions including saving, investing, and decumulating wealth to employees and retirees. Where in the past, employees in many countries relied on social security and employer-sponsored defined benefit pension plans, with the increasing shift to defined-contribution pension plans, households are now being given greater control and responsibility over the long-term investments funding their retirement. At the same time, consumers have to find their bearings in a market characterized by a growing complexity which requires both a firm understanding of increasingly sophisticated products and the ability to judge the quality of guidance received about these products.

In Germany, this trend towards consumer autonomy has been further accelerated by two developments. First, the 2001 reform of the public pension system transformed a statutory pension scheme established at the foundation of the Federal Republic of Germany which had provided generations of retirees with sufficient funds into a system featuring multiple pillars of old-age provision. Specifically, this shift involved a substantial reduction of state-granted benefits and ever since requires employees to participate in state-subsidized pension plans (most prominently the so-called Riester plan) as well as occupational and private pension plans in order to fill the gap in retirement income. The second aspect relates to how German households have traditionally accumulated wealth: large parts of the population predominantly rely on savings deposits and thus forego excess returns of equity investments. While this extreme risk aversion has always been a challenge to profitable asset management, the ongoing period of interest rates next to zero renders established savings patterns entirely ineffective and urges for new investment strategies to provide for retirement. Taken together, these developments turn millions of German households into financial market participants, even though the vast majority have below-average experience as compared to individual investors in other economies like, e.g., the U.S. with a long-term equity culture.

Against this background, a natural question to ask is whether today's households are well-equipped to successfully manage their personal financial affairs. In this review, we address this question and thereby focus on consumers' financial literacy, i.e. their knowledge of key financial concepts as well as their ability to apply this knowledge to make informed financial decisions. ${ }^{1}$

To preview the evidence provided by some of the studies we survey in greater detail in subsequent sections of the paper, research not only documents generally low levels of financial literacy but also finds large heterogeneity in financial literacy across the population. For example, Bucher-Koenen and Lusardi (2011) assess financial literacy in Germany and provide evidence that knowledge of basic financial concepts is particularly low among women, the less educated, and those

\footnotetext{
${ }^{1}$ Section 2.1 of this paper provides details on the conceptualization of financial literacy.
} 
living in East Germany, hence suggesting that economically vulnerable groups are placed at further disadvantage by their lack of financial knowledge.

Moreover, low levels of financial literacy have been linked to suboptimal financial behavior likely to have long-term consequences. Hilgert et al. (2003) find that low literate individuals are generally less likely to engage in a wide range of recommended financial practices. More specifically, Bucher-Koenen (2011) finds that Riester participation is disproportionately low among those German households with the lowest levels of financial literacy, although this group is eligible for the relatively highest government subsidies (see, e.g., Coppola and Gasche 2011). In the U.S., Choi et al. (2011) investigate contributions to 401(k) plans by employees who are eligible for an employer match and find that a large fraction of these employees either do not participate at all or contribute less than the amount required to be granted the full employer match, thus foregoing matching contributions which cumulate to substantial losses over time. These and other findings in the literature have sparked public discussion pointing to a need for financial literacy in a world in which individuals now shoulder greater personal financial responsibility. Accordingly, the assessment of consumers' financial competence as well as the effect of financial education initiatives on economic outcomes has attracted considerable attention in recent years and the academic literature on financial literacy is rapidly evolving.

We conducted an ad-hoc query using the Web of Science ${ }^{2}$ and searched for the terms 'financial literacy' or 'financial knowledge' in the publication titles. Figure 1 reports the rapid increase in publications on the topic as of March 2016. Specifically, the first 3-year period from 2002 to 2004 featured an average of one publication per year whereas roughly 26 papers per year were published between 2013 and 2015. As can be also inferred from Fig. 1, the increasing relevance of financial literacy becomes even more obvious when using citations generated by financial literacy publications as a benchmark. From 2004 to 2006, the Web of Science database counts no more than two citations per year while in the most recent 3-year period, i.e. 2013-2015, this number jumps to an annual average of 346 citations.

Table 1 lists the 20 most frequently cited publications we obtained from our Web of Science query. Interestingly, these top-cited papers are published in journals covering a broad array of disciplines in economics and business administration, including accounting, economics, economic psychology, finance, and marketing. The most important publication outlet is the Journal of Consumer Affairs, i.e. a marketing-related journal, which accounts for a total of eight publications in the top 20. Economics journals come second and the remaining disciplines close behind.

In this survey, we offer an assessment of the voluminous body of literature on the measurement and the determinants of financial literacy. In addition, we assess the literature dealing with the effectiveness of financial education when it comes to improving financial literacy and financial behavior. At this, we complement the

\footnotetext{
2 The Web of Science (formerly known as Web of Knowledge) is a scientific citation index maintained by Thomson Reuters which provides access to multiple databases that reference cross-disciplinary research and allows for in-depth exploration of specialized areas within an academic or scientific discipline.
} 
Publications per year

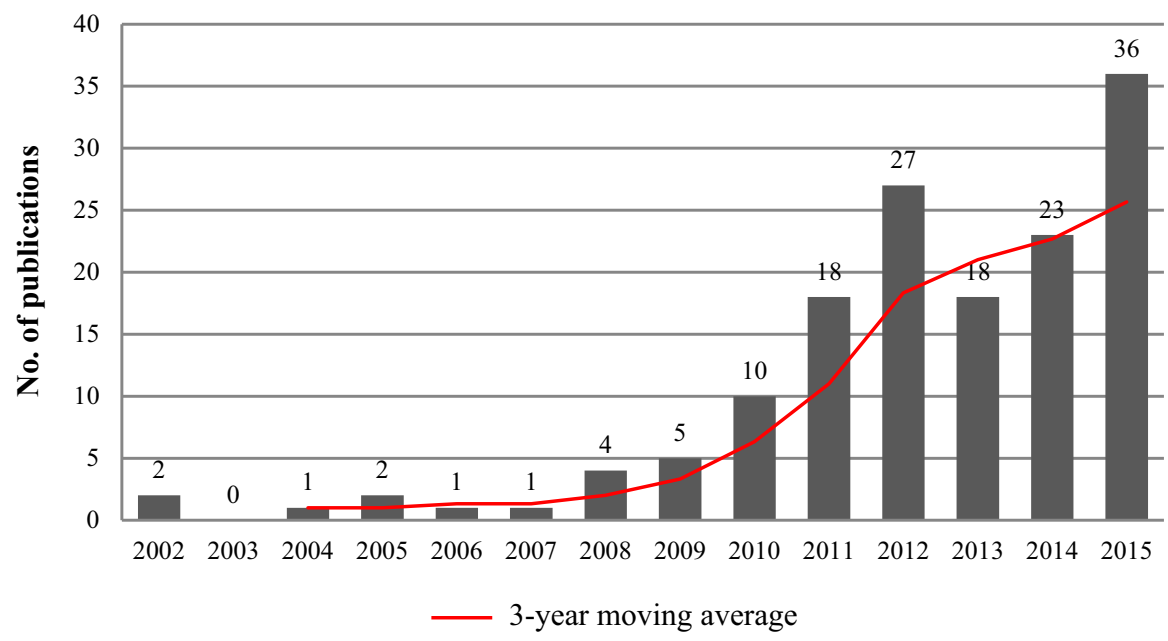

Citations per year

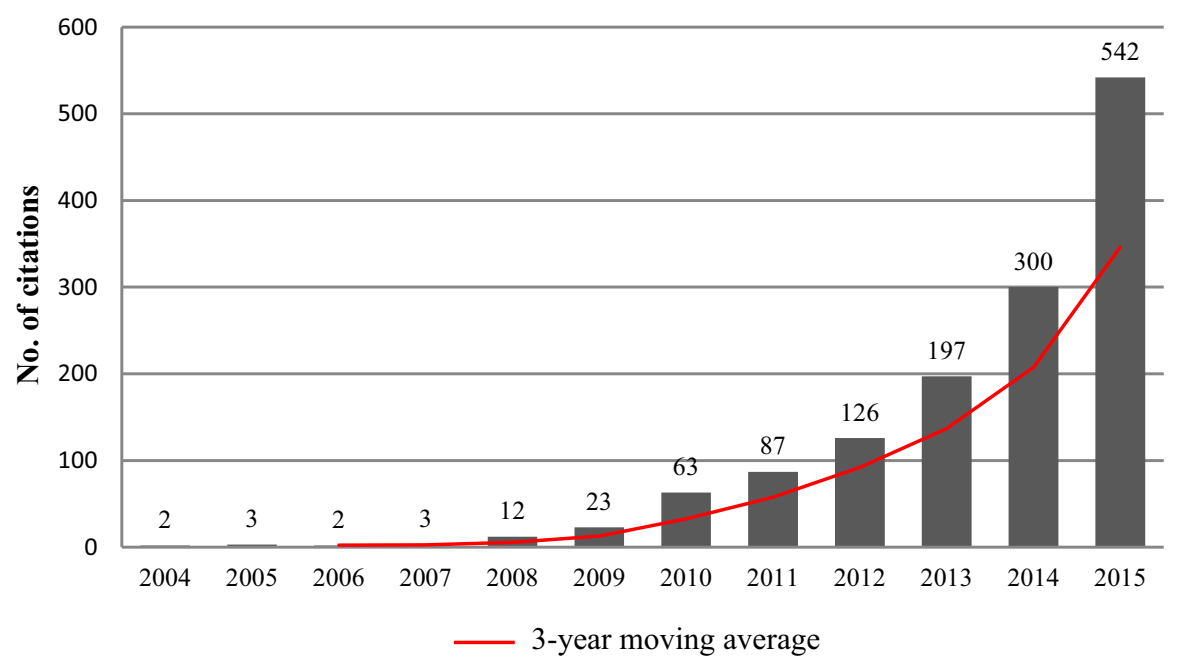

Fig. 1 Number of and citations triggered by publications on financial literacy and financial knowledge, per year. Notes: This figure plots the number of studies with the terms "financial literacy" and "financial knowledge" in the title. Numbers stem from search quieries using the scientific citation index "Web of Science" which provides access to multiple databases that reference cross-disciplinary research. See Sect. 1 for further details

excellent reviews provided by Hastings et al. (2013) and Lusardi and Mitchell (2014) along at least three different lines. First, while these surveys focus on U.S.-based evidence, we adopt a different perspective and instead put emphasis on what is known about financial literacy in Germany, since German consumers face 


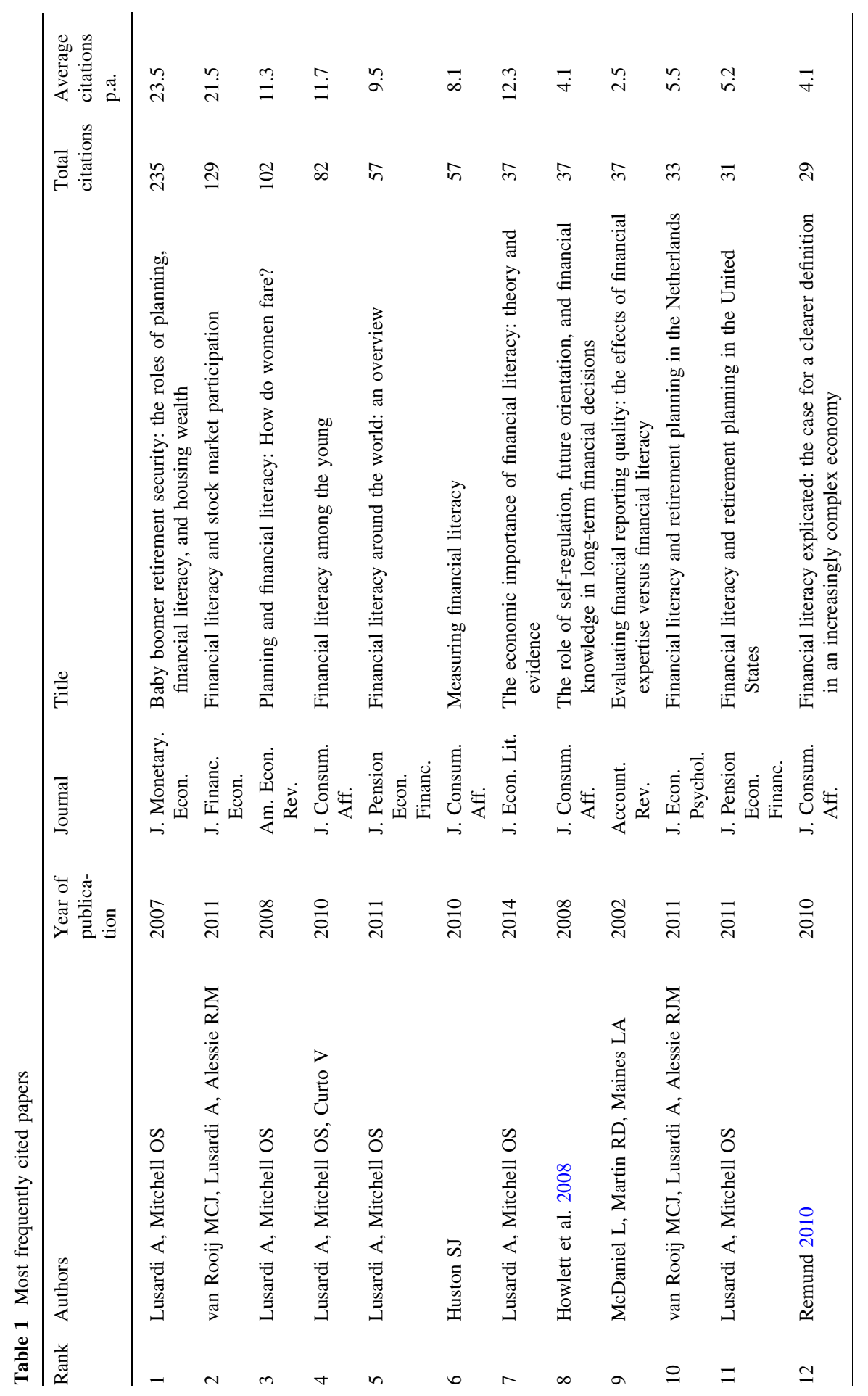




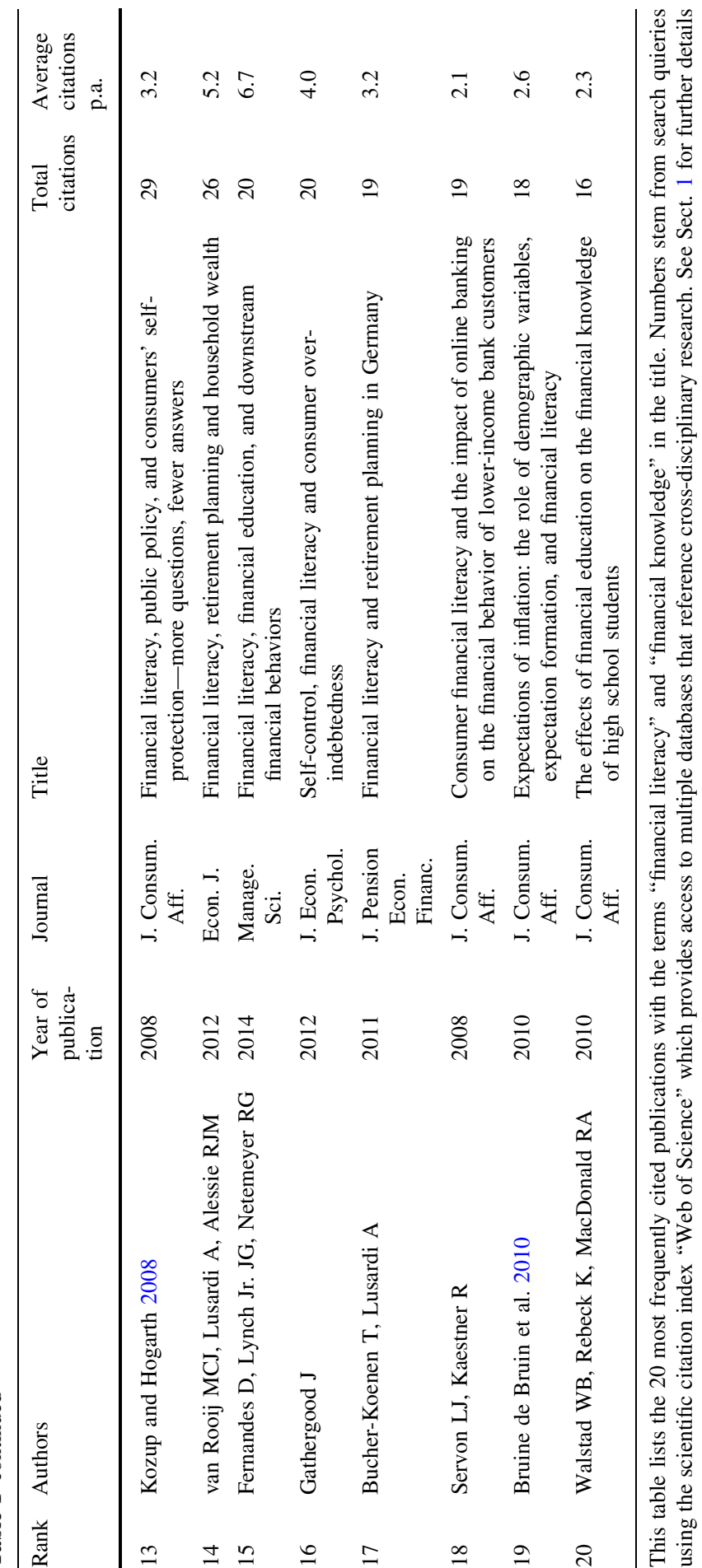


financial decisions substantially different from those of U.S. their counterparts. Wherever possible, we supplement existing findings with recent descriptive evidence of German households' financial literacy levels based on the novel Panel on Household Finances (PHF) dataset, a large-scale survey administered by the Deutsche Bundesbank and representative of the financial situation of households in Germany. $^{3}$

Second, we review the role of individuals' financial literacy for the use of professional financial advice. Recently, a lot of contributions have addressed the question whether financial advice may substitute for financial capabilities or if the two approaches to improve consumer financial decision making instead should rather be considered complements. One goal of this paper is to present a comprehensive survey of the literature contributions discussing this question which seeks to inform policymakers about the effectiveness of interventions regulating the supply side of financial products and services on the one hand versus enabling the demand side by means of financial education initiatives on the other hand.

Third, we aim at providing the reader with some of the tools necessary to contribute to the research on financial literacy. To this end, we describe different methodological approaches to proxy for individuals' financial capabilities absent a direct measure of financial literacy. Moreover, we highlight potential endogeneity concerns when it comes to establishing cause-and-effect relationships as well as methodological approaches to address endogeneity in the context of financial literacy research. Finally, we supplement the literature review with a number of useful overviews over the host of different sources providing the raw data necessary to address relevant research questions.

While this review focuses on the empirics of financial literacy research, the body of literature on individuals' financial knowledge and abilities also comprises important theoretical work (e.g. Delavande et al. 2008; Jappelli and Padula 2013, 2015; Lusardi et al. 2013). Most of the theoretical contributions develop intertemporal consumption frameworks to model individuals' decision to invest in financial literacy as well as its effect on households' general savings and investment decisions, i.e. endogenizing their decision to invest in financial knowledge. ${ }^{4}$

The remainder of the paper is structured as follows. Section 2 discusses conceptualizations of financial literacy and describes and assesses different approaches to measure it. In Sect. 3, we review the evidence on financial literacy levels for various different economies around the world, while Sect. 4 surveys the literature on the determinants of financial literacy. Section 5 discusses the voluminous body of literature contributions investigating the link between financial literacy and financial behavior and addresses endogeneity concerns arising when capturing this connection. Section 6 reviews alternative approaches proposed to improve consumers' financial behavior as well as an evaluation of their effectiveness. Section 7 concludes, draws policy implications, and suggests avenues for further research.

\footnotetext{
3 See the Appendix to this paper for a detailed description of the PHF data.

${ }^{4}$ For an excellent review of the theory of financial literacy, the reader is referred to Lusardi and Mitchell (2014).
} 


\section{Measuring financial literacy}

\subsection{Conceptual definitions}

How do consumers perform when it comes to managing their personal finances? Clearly, assessing the role of financial literacy as an input to effective financial decision making first of all requires a clear definition of financial literacy as well as a universal understanding of how it is conceptualized.

\subsubsection{Definitions of financial literacy}

The term financial literacy was introduced in the U.S. by the Jump\$tart Coalition for Personal Financial Literacy in 1997, defining the concept as "the ability to use knowledge and skills to manage one's financial resources effectively for lifetime financial security". Later, also in the U.S., this characterization was adopted in a universal definition provided by the President's Advisory Council on Financial Literacy (PACFL 2008). However, Hung et al. (2009), in their review of competing financial literacy concepts, find that the literature has proposed several definitions and lacks a universally accepted notion of what financial literacy really means. They document a large variety of conceptual definitions and show that each of them stresses different dimensions of financial literacy, i.e. actual and perceived knowledge of financial matters as well as the ability to apply that knowledge, but also individual financial experience and even sound financial behavior. In another extensive review of financial literacy operationalizations, Huston (2010) surveys 71 studies using 52 different data sets and corroborates that there is no such thing as a standardized conceptualization of financial literacy. $72 \%$ of studies did not even include an explicit definition. Moreover, there was no universally accepted meaning of financial literacy among those studies which did propose financial literacy definitions. Finally, the terms financial literacy and financial knowledge were used interchangeably by almost half of all studies under review. Like other standardized concepts of literacy such as computer literacy or health literacy, however, Huston (2010) stresses that "financial literacy should be conceptualized as having two dimensions-understanding (personal finance knowledge) and use (personal finance application)" (p. 306). A similar understanding is given in Hung et al. (2009), who consolidate the various definitions they review and propose an overarching conceptualization specifying financial literacy as the "knowledge of basic economic and financial concepts, as well as the ability to use that knowledge and other financial skills to manage financial resources effectively for a lifetime of financial wellbeing" (p. 12). A recent definition employed in the 2012 Program for International Student Assessment (PISA) has been provided by the Organization for Economic Cooperation and Development (OECD 2014) and includes both the knowledge and the application domain: "Financial literacy is knowledge and understanding of financial concepts and risks, and the skills, motivation and confidence to apply such knowledge and understanding in order to make effective decisions across a range of financial contexts, to improve the financial well-being of individuals and society, and to enable participation in economic life" (p. 33). 


\subsubsection{Cognitive abilities versus financial literacy}

There is an ongoing debate as to how financial literacy is distinct from related concepts like numeracy and cognitive abilities. Hastings et al. (2013) document that respondents with higher cognitive abilities and more comfortable with numerical calculations on average exhibit higher levels of financial literacy. They also review a number of studies which find a positive relationship between cognitive abilities and numeracy on the one hand and sound financial behavior on the other hand (e.g., Banks and Oldfield 2007; Grinblatt et al. 2009; Christelis et al. 2010). Thus, Hung et al. (2009) argue that, for designing effective programs to improve financial literacy, it is important to differentiate general cognitive abilities from core aspects of financial literacy. ${ }^{5}$ Lusardi et al. (2010) address this point of criticism by analyzing both a measure of financial literacy and a proxy for cognitive ability obtained from the National Longitudinal Survey of Youth (NLSY). On the one hand, the authors confirm a positive correlation between financial literacy and cognitive ability. However, they also show that cognitive factors cannot account for the entire variation in measured financial literacy levels, thereby leaving room for other dimensions of financial literacy.

\subsection{Test-based measures of financial literacy}

In their review of financial literacy measures used in 18 different studies, Hung et al. (2009) document that test-based or performance-based approaches have become prevalent in order to capture financial literacy. Test questions are usually drawn from household surveys and refer to knowledge of financial products (e.g., knowledge of stocks, bonds, mutual funds, or mortgages), knowledge of financial concepts (e.g., inflation, risk diversification, or the time value of money), and to general mathematical and numerical skills. The individual level of financial literacy of a given survey respondent is then obtained using different means of aggregating these questions. While some studies measure financial literacy using simple indicator variables (Jappelli 2010; Gathergood 2012), several other authors rely on more advanced techniques such as principal component analysis (e.g. Behrmann et al. 2012; Klapper et al. 2013; Lusardi et al. 2014), iterated principal factor analysis (e.g. van Rooij et al. 2011b), or cluster analysis (e.g. Lusardi and Tufano 2015). Yet, results regarding the relationship of financial literacy with financial behavior have been shown to be largely robust to the technique applied to condense the underlying questions.

\subsubsection{The Big Three}

Hung et al. (2009) show that the various test-based measures they review are generally highly correlated with each other and when the questions are worded identically, answers feature high test-retest reliability across different survey waves. Thus, in the following, we will focus on three specific test questions introduced by

\footnotetext{
${ }^{5}$ For a comprehensive evaluation of initiatives to improve consumers' financial literacy, see Sect. 6.1.
} 
Lusardi and Mitchell (2008) in a special module of the 2004 Health and Retirement Study (HRS). ${ }^{6}$ These questions have been widely adopted in the U.S. and elsewhere and have become known as the Big Three. ${ }^{7}$ The first one of this parsimonious set of questions addresses individuals' numeracy and their ability to do simple calculations and is worded as follows ${ }^{8}$ :

Suppose you had $\$ 100$ in a savings account and the interest rate was $2 \%$ per year. After 5 years, how much do you think you would have in the account if you left the money to grow:

[more than \$102; exactly \$102; less than \$102; do not know; refuse to answer.]

The second question refers to inflation and money illusion:

Imagine that the interest rate on your savings account was $1 \%$ per year and inflation was $2 \%$ per year. After 1 year, would you be able to buy: [more than, exactly the same as, or less than today with the money in this account; do not know; refuse to answer.]

Finally, the third question tests if respondents are familiar with the concept of risk diversification:

Do you think that the following statement is true or false? 'Buying a single company stock usually provides a safer return than a stock mutual fund.'

[true; false; do not know; refuse to answer.]

Although the Big Three generally do not demand advanced financial knowledge, only $34 \%$ of respondents in the original survey were able to answer all three questions correctly (Lusardi and Mitchell 2014). Straightforwardly, individuals who fail to correctly answer the first two questions will likely experience difficulties when facing even basic financial decisions characterized by an investment today and returns in the future. Providing the correct answer to the third question requires some knowledge about stocks and stock mutual funds as well as about the concept of risk diversification and thus indicates if respondents are able to effectively manage their financial assets.

\subsubsection{Beyond the Big Three}

In subsequent analyses, surveys were extended by additional questions beyond the Big Three so as to capture other dimensions of financial literacy. Specifically, Lusardi and Mitchell added two more items measuring knowledge in asset pricing and mortgages to the 2009 National Financial Capability Study (NFCS). In a recent large scale survey of financial literacy levels in more than 140 national economies, Klapper et al. (2015) elicit four quiz questions closely related to the Big Three. Thereby, the survey addresses four fundamental concepts for financial decision-

\footnotetext{
6 The Health and Retirement Study (HRS) is a survey among U.S. households aged 50 and older. See Table 3 for details on the different surveys employed in the studies we review in this paper.

7 See Table 2 for a survey.

${ }^{8}$ Correct answers are displayed in bold.
} 


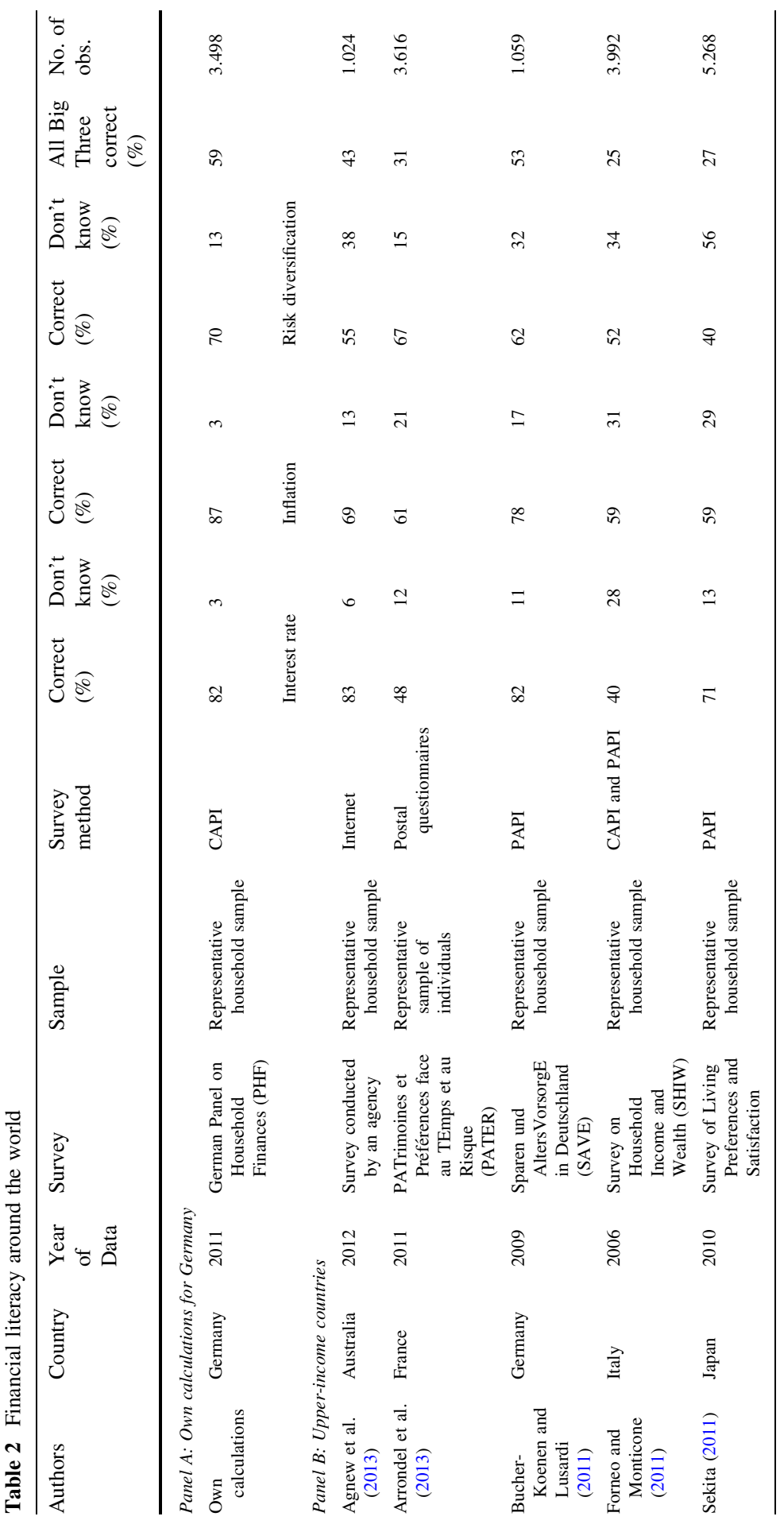




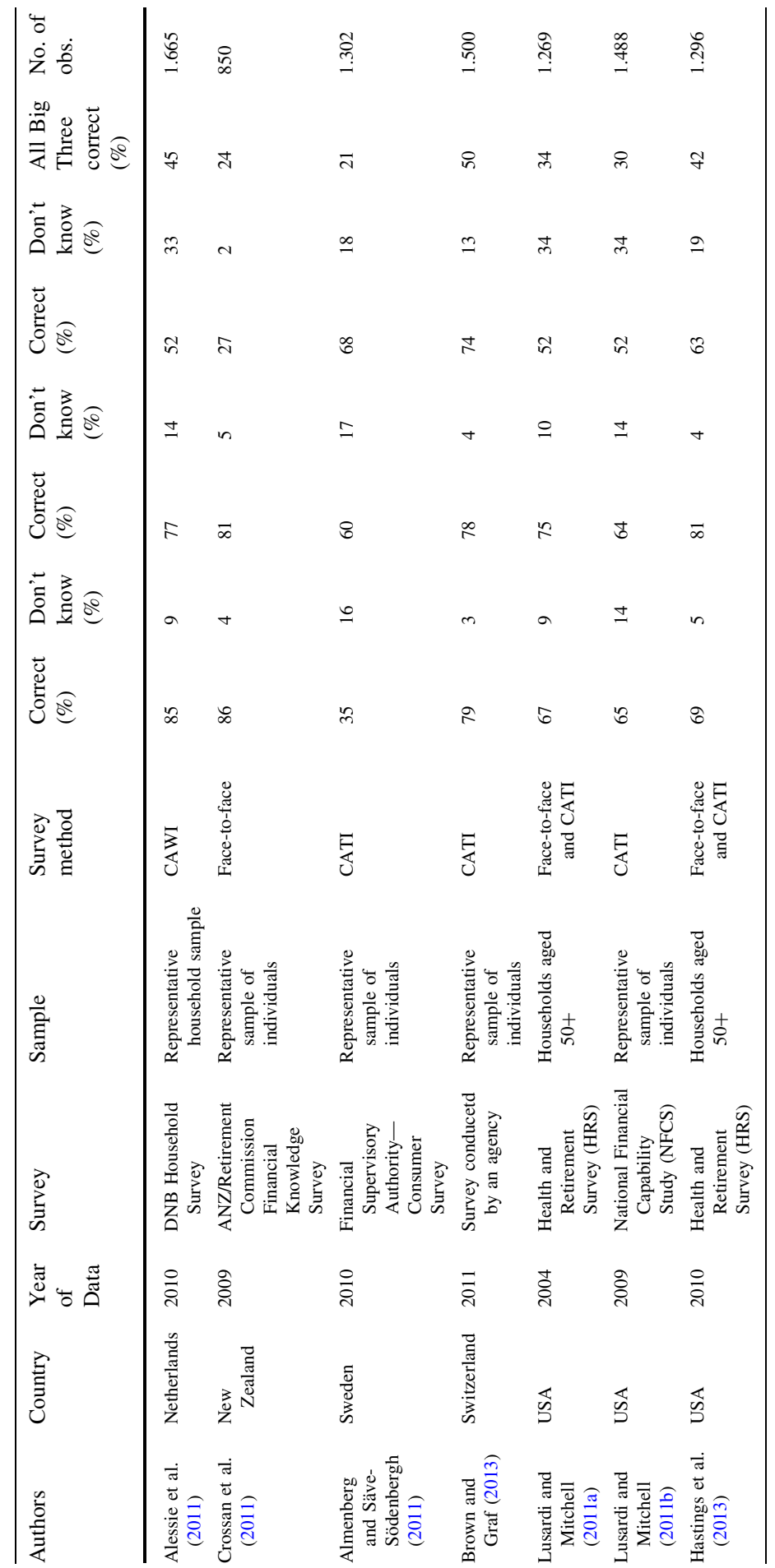




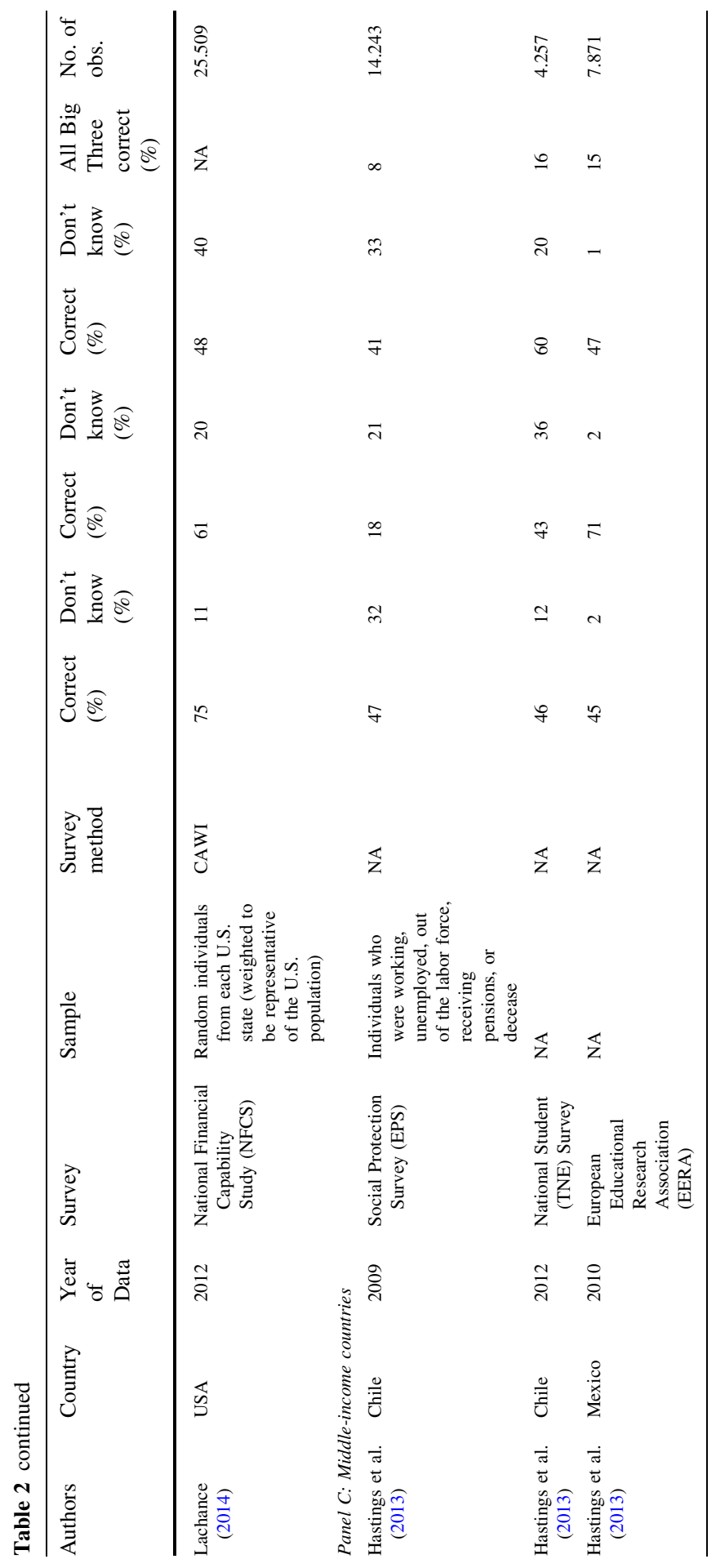




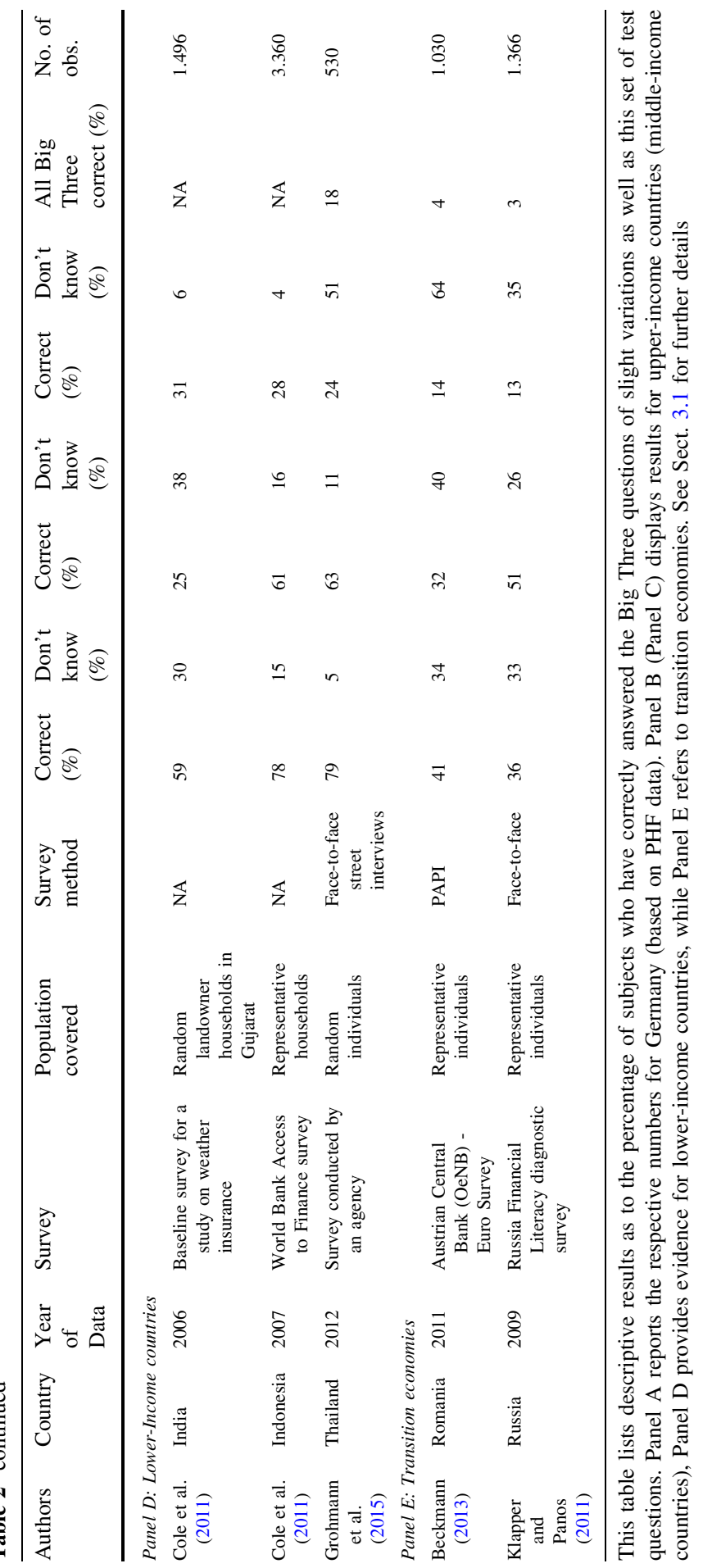


making: risk diversification ${ }^{9}$ (related to the third question of the Big Three), inflation $^{10}$ (very similar to the second question of the Big Three), numeracy ${ }^{11}$ (new question, previously not included in the Big Three) and compound interest ${ }^{12}$ (an advancement of the first question of the Big Three as this question actually refers to the concept of interest compounding).

Recently, the OECD has adopted an even broader perspective on the measurement of financial literacy for the 2012 PISA assessment (OECD 2014). An expert group consisting of regulators, academics and practitioners from different countries designed questions in three dimensions: knowledge and understanding (content), approaches and mental strategies (processes) and financial situations (contexts), reflecting real-life situations of 15-year-old students. The assessment consists of 40 finance-related questions as well as questions in the areas of mathematics and reading abilities. Students were asked to analyze simple graphs, calculate interest rates or evaluate payment checks and invoices. Thus, the financial literacy measure designed for the PISA assessment differs from the Big Three along two dimensions. First, the questions asked cover a much larger array of financial issues and place emphasis on financial decisions faced by 15 -year-old students. Second, due to a more extensive battery of questions, financial literacy levels elicited in the PISA assessment capture more nuances of knowledge and abilities related to personal finance matters.

\subsubsection{Caveats of test-based financial literacy measures}

Although test-based approaches towards measuring financial capabilities-most prominently the Big Three-have now become the international benchmark for the assessment of financial literacy, there is little evidence on whether this set of questions is indeed a superior approach to capturing financial literacy. Hastings et al. (2013) emphasize that it is generally unclear if questions are a suitable means for measuring financial capability and, if so, which questions lend themselves most effectively for identifying it. Specifically, the authors criticize that surveys eliciting financial literacy levels do not incentivize respondents to provide carefully considered answers reflecting their actual knowledge. Besides, study designs usually do not permit participants to tap into other sources of information in order to prepare their decisions. Yet, accessing the internet, talking to friends and family, or consulting with a financial

\footnotetext{
9 The first question reads: "Suppose you have some money. Is it safer to put your money into one business or investment, or to put your money into multiple businesses or investments?".

10 The wording of the second question is: "Suppose over the next 10 years the prices of the things you buy double. If your income also doubles, will you be able to buy less than you can buy today, the same as you can buy today, or more than you can buy today?".

11 The third question reads: "Suppose you need to borrow 100 US dollars. Which is the lower amount to pay back: 105 US dollars or 100 US dollars plus three percent?".

12 The wording of the fourth question is: "Suppose you put money in the bank for two years and the bank agrees to add $15 \%$ per year to your account. Will the bank add more money to your account the second year than it did the first year, or will it add the same amount of money both years?".
} 
advisor $^{13}$ are important channels of expertise used by many consumers to compensate for their individual lack of financial literacy when making real-life financial decisions. Ignoring them likely biases the observed impact of financial literacy on financial behavior.

Another shortcoming of test-based measures of financial literacy is their sensitivity to framing. Specifically, Lusardi and Mitchell (2011a, b) and van Rooij et al. (2011b) document that the answers of survey participants differ significantly based on the wording of the test questions. In fact, the percentage of correct answers doubled in the latter study when the wording for the third question of the Big Three was "buying company stock usually provides a safer return than a stock mutual fund" as compared to phrasing the question reversely, i.e. "buying a stock mutual fund usually provides a safer return than a company stock". Hence, Lusardi and Mitchell (2014) conclude that some answers classified as "correct" might instead reflect simple guessing of respondents and highlight that measurement error might be an issue when eliciting financial ability based on test questions. ${ }^{14}$

Finally, Meyer et al. (2015) document that the quality of data obtained from household surveys has declined in recent years. This development owes to increasing non-participation of households (unit nonresponse), a tendency of not answering certain questions (item nonresponse), and, finally, increased measurement error due to greater inaccuracy of the participating households when answering the survey questions. Although this trend is not limited to items related to financial literacy, it constitutes an additional issue regarding the reliability of recent surveys on financial literacy.

\subsection{Self-assessed financial literacy}

An alternative approach to eliciting financial literacy levels which has also become prevalent in the literature involves asking survey respondents for a self-assessment of their financial capabilities. The corresponding item is usually worded as follows (Lusardi and Mitchell 2014, p. 11) ${ }^{15}$ :

On a scale from 1 to 7 , where 1 means very low and 7 means very high, how would you assess your overall financial knowledge?'

Comparing test-based and self-assessed financial literacy, the literature reveals that individuals tend to be overly confident about how much they really know (e.g., Agnew and Szykman 2005). ${ }^{16}$ Given the far-reaching consequences of many

\footnotetext{
13 For details regarding the impact of individuals' financial literacy on their use of financial advice, see Sect. 6.2.

14 See Sect. 5.1 for a detailed discussion of how measurement error affects inference.

15 Note that some studies use alternative concepts of self-assessed financial literacy, which, however, yield broadly comparable results. Specifically, Hastings et al. (2013) use the 2009 NFCS to compare three different measures of self-reported financial capability (self-assessed overall financial knowledge, selfassessed mathematical knowledge, and self-assessed capability at dealing with financial matters) for various demographic subgroups and find that the different constructs are all highly correlated with each other.

16 Exceptions to this behavioral trait are Japanese individuals (Sekita 2011).
} 
financial decisions, this overconfidence might be a problem, especially in situations where individuals are not aware of this bias (Lusardi and Mitchell 2014). In particular, older people tend to have a high confidence in their financial literacy although they do rather poorly on the test questions as well as with respect to their actual financial behavior (Lusardi and Tufano 2015; Lusardi and Mitchell 2011a, c; Gamble et al. 2015). In a cross-country study including American, Dutch, and German households, Bucher-Koenen et al. (2016) recently document gender differences not only in test-based but also in self-reported levels of financial literacy. Specifically, women are less likely to respond correctly to the Big Three and also assign themselves lower scores than men, i.e. suggesting overconfidence in financial capabilities which seems especially pronounced among males. In another recent study for Germany, Bannier and Neubert (2016a) corroborate the gender gap in confidence regarding financial literacy. Analyzing data drawn from the SAVE survey ${ }^{17}$ they show that, while men are generally overconfident with respect to their financial knowledge, women instead tend to be underconfident. Finally, recent contributions on self-assessed versus test-based measures discuss whether or not high levels of confidence in one's own financial knowledge may be beneficiary for individuals. While Lusardi and Mitchell (2014) highlight the problems associated with overconfidence, Bannier and Neubert (2016a) document a positive correlation between overconfidence and investment performance for the group of highlyeducated men. ${ }^{18}$

An interesting question is how test-based and self-assessed levels of financial literacy relate to each other. Indeed, the literature finds that self-assessed financial literacy and observed financial behavior do not always correlate strongly (Collins et al. 2009; Hastings and Mitchell 2011). Agnew and Szykman (2005), for instance, document a median correlation of 0.49 between actual and self-assessed financial literacy scores, a finding which is qualitatively corroborated in Lusardi and Mitchell (2009) and Parker et al. (2012). Moreover, both types of measures have been shown to be individually associated with financial decisions (e.g., Hastings et al. 2013; Asaad 2015; Allgood and Walstad 2016). Specifically, Parker et al. (2012) show that both self-reported and test-based financial literacy are predictive for retirement planning and savings. Likewise, van Rooij et al. (2011b) find that both self-assessed and objectively measured financial literacy predict individuals' propensity to hold stocks. Bannier and Neubert (2016b) extend this research by showing that selfassessed financial knowledge associates with riskier investments (in discount certificates, hedge funds), while objectively measured financial literacy correlates

\footnotetext{
${ }_{17}$ Unlike in the DHS and SHARE surveys, replies in the PHF and SAVE datasets stem from one individual per household. As described in Bucher-Koenen and Lusardi (2011), SAVE draws on a randomly chosen household member who has information on the household's finances. Thus, the individual completing the questionnaire is not necessarily the household head. Consistent with this approach, interviews in the PHF were conducted with financially knowledgeable persons familiar with the household's financial situation (one per household), who again need not necessarily be the head of the surveyed household. Hence, owing to their largely similar elicitation modes, the PHF and SAVE data are to a great extent comparable regarding respondents' answers.

18 At the same time, however, Bannier and Neubert (2016a) find a negative association between female underconfidence and financial planning outcomes, which turns out statistically significant for the subgroup of highly-educated women.
} 
strongly with less risky standard investments (in stocks, mutual funds, or real estate trusts). Moreover, the authors observe a gender gap in that this difference in risk taking based on individuals' own perception of their financial abilities is more pronounced for women. In a recent study, Allgood and Walstad (2016) use a combined measure of test-based and self-assessed financial literacy and find that both financial literacy measures appear to independently correlate with financial behavior, leading them to conclude that self-assessed financial literacy may be as important as test-based financial literacy in explaining financial outcomes. Finally, Kramer (2014) and von Gaudecker (2015) compare individuals' test-based financial literacy levels with how financially literate they perceive themselves and suggest a role for overconfidence which reduces individuals' propensity to demand professional financial advice (see Sect. 6.2).

\subsection{Proxies for financial literacy}

\subsubsection{Socio-demographic proxies}

Absent a survey-based measure of financial literacy, a number of studies have turned to different proxies for subjects' financial literacy levels. Given the robust correlations between several socio-demographic characteristics and measured financial literacy (see Sect. 4.1), several contributions lacking an observable measure of financial capabilities exploit this evidence and use respondents' demographics in order to capture their financial literacy. Corresponding proxies for financial sophistication used in the literature include (disposable) income and wealth (Dhar and Zhu 2006; Vissing-Jorgensen 2003; Calvet et al. 2007, 2009) as well as age (Calvet et al. 2007, 2009; Georgarakos and Pasini 2011), educational attainment (Christiansen et al. 2008; Calvet et al. 2007, 2009), professional status (Calvet et al. 2009), and even IQ (Grinblatt et al. 2011, 2012). Likewise, both Chalmers and Reuter (2012) and Hackethal et al. (2012) use subsets of these demographics to proxy for financial literacy in their analyses.

A methodologically advanced approach to infer a demographics-based proxy of financial literacy recently applied in Stolper (2016) combines individuals' demographic characteristics as well as directly measured levels of financial literacy by drawing on two different datasets each of which contains an identical set of demographics for a given cohort. The difference between the two datasets, however, is that only one of them contains the explanatory variable of interest, i.e. a direct measure of financial literacy, while the other features the financial outcome of interest but lacks a financial literacy measure. To overcome this data limitation, the author resorts to the imputation method proposed by Browning and Leth-Petersen (2003) and designed to link datasets featuring the above-mentioned properties. Following Graham et al. (2009) and Korniotis and Kumar (2013), who apply this approach to infer individuals' perceived competence and smartness, respectively, the author proceeds in two steps to obtain a demographics-based financial literacy variable. First, he estimates an empirical model of financial literacy using the first wave of the PHF survey which contains both a direct measure of financial literacy and several of the demographic characteristics that have been shown to explain a 
significant proportion of the cross-sectional variation in people's financial literacy levels (see Sect. 4.1). In a second step, the author then employs this model to predict the financial literacy levels of the households sampled in the primary dataset which only contains the respective demographics. Specifically, he uses the coefficient estimates obtained from the PHF-based model and plugs in the relevant demographic characteristics available in the primary dataset in order to construct a variable capturing predicted financial literacy.

\subsubsection{Outcomes-based proxies}

Given the drawbacks of test-based measures, some have proposed alternative approaches towards capturing financial literacy. Instead of surveying households, a natural way to infer financial literacy levels from other available information is to look at individuals' readily observable financial behavior and use the quality of their financial decisions as a proxy for their financial literacy. Such outcomesbased proxies for financial literacy comprise observed risk diversification in equity portfolios (Goetzmann and Kumar 2008; Grinblatt and Keloharju 2001), prior investment experience (Goetzmann and Kumar 2008; Nicolosi et al. 2009; Seru et al. 2010), and the propensity to invest in complex financial instruments (Genesove and Mayer 2001; Goetzmann and Kumar 2008). Following this idea, Calvet et al. (2009) draw on the security accounts of a large-scale panel comprising 4.8 million Swedish households and construct an index of financial sophistication based on the sampled households' (observable) ability to avoid poor financial decisions such as holding underdiversified portfolios, displaying inertia in risk taking, and exhibiting a disposition effect. Clearly, such an outcomes-based strategy crucially hinges on increased data availability. Nevertheless, as Hastings et al. (2013) point out, using consumers' actual financial behavior as an indicator may be a more effective approach to predict future outcomes than the existing standard which, as described above, relies on more general proxies of financial literacy such as the Big Three.

\section{Financial literacy around the world}

Few studies lend themselves for an inclusion to a cross-country assessment of general financial literacy levels of consumers across different countries. Straightforwardly, a major data limitation is that we have to compare identical literacy measures that have been applied in studies carried out in many countries, ultimately leaving us with only few cross-country assessments.

\subsection{Financial literacy of adult consumers}

To qualify for inclusion, all studies under review with respect to financial literacy levels of adults must employ the original set of the Big Three or slight variations of it; Table 2 reports the corresponding results and provides supplementary descriptives obtained from the PHF survey. In what follows, we discuss these results in 
light of recent contributions to the literature as well as the various studies Hastings et al. (2013) and Lusardi and Mitchell (2014) review in their survey papers. ${ }^{19}$

Table 2 is structured as follows. Panel A reports results for our analyses on the PHF survey. Subsequent panels document previous findings documented in the literature. Panel B (Panel C) displays results for upper-income countries (middleincome countries), Panel D provides evidence for lower-income countries, while Panel E refers to transition economies.

Generally, we document large cross-country variation in proficiency levels. As can be seen in Table 2, the share of individuals answering all Big Three questions correctly amounts to 59\% (based on the PHF data) and 53\% (according to the SAVE data) of respondents. This implies that financial literacy levels documented for Germany range among the highest worldwide. Among respondents in the two transition economies Russia and Romania, by contrast, the respective numbers are as low as $4 \%$. Moreover, while proficiency levels are relatively highest in upper-income countries (Panel B), absolute levels of financial literacy are still rather low in this group. The mean fraction of survey participants answering all Big Three questions correctly is 35\% for these countries as compared to only $13 \%$ for middle-income countries (Panel C) and $4 \%$ for transition economies (Panel E). ${ }^{20}$ When disaggregating the numbers at the level of the individual question, the tests that require knowledge about interest rates and inflation seem roughly equally difficult for survey participants. Specifically, the mean fraction of correct answers amounts to $63 \%$ for the question on interest rates and $60 \%$ for the question on inflation. Corroborating the evidence documented in the original study conducted by Lusardi and Mitchell (2008), the question on risk diversification appears to be the most difficult one. Here, on average only $46 \%$ of respondents were able to provide the correct answer.

Lusardi and Mitchell (2014) document that, despite their parsimonious design, the Big Three do a good job differentiating individual levels of financial capabilities in the population. Specifically, 34.3\% of respondents of the 2004 HRS pioneer survey got all, $35.8 \%$ got two, $16.3 \%$ got one, and $9.9 \%$ got none of the questions right. Based on our evidence drawn from the German PHF data, we find that, by and large, this feature still holds. When focusing on the likelihood of answering either one of the three questions correctly, we find that $59.0 \%$ of respondents answered all Big Three questions correctly, while only $26.4 \%(10.0,4.7 \%)$ got two (one, zero) questions right.

Recently, Klapper et al. (2015) provide a direct cross-country comparison of financial literacy levels by analyzing data from the Standard \& Poors Ratings Services Global Financial Literacy Survey (S\&P Global FinLit Survey) conducted in 2014. ${ }^{21}$ In this survey, the four test questions introduced in Sect. 2.2 were added to the Gallup World Poll survey and answered by about 150,000 randomly selected adults (aged 15

\footnotetext{
${ }^{19}$ Note, however, that findings across the different studies are not always readily comparable, since the individual surveys naturally differ in terms of year of data, survey mode, and size of sampled cohort.

${ }^{20}$ Note that mean values reported in this section are equally-weighted across the sampled studies.

${ }^{21}$ In a related study, Japelli (2010) conducts a cross-country assessment of economic literacy in 55 countries based on the IMD World Competitive Yearbook (WCY). Note, however, that Japelli (2010) differs from the studies surveyed above in two respects. First, economic literacy is distinct from financial literacy. Second, he provides insights on literacy levels of senior business leaders, while our focus is on private households.
} 
and above) in 144 national economies either face-to-face or by telephone. The authors classify an individual as being financially literate if she answers at least three of the four test questions correctly. They also document a large heterogeneity across countries. Internationally, Australia, Canada, Denmark, Finland, Germany, Israel, the Netherlands, Norway, Sweden, and the United Kingdom host the most financially knowledgeable citizens: more than $65 \%$ of adults in these countries are classified as being financially literate. With a fraction of $71 \%$ literate citizens, Scandinavian countries lead the ranking. Germany follows suit (66\%). By contrast, the percentage of financially literate adults turns out remarkably low for many countries in South America, Africa, and in South Asia. Generally, roughly only one in three adults is classified as financially literate in about half of the countries included in the survey. With a proportion of only roughly $13 \%$ financially literate adults, the Republic of Yemen as well as Afghanistan and Albania score lowest in this cross-country assessment of individual financial ability.

\subsection{Financial literacy of adolescents}

Unlike most other datasets discussed in this review, a comprehensive cross-country survey conducted on behalf of the OECD has recently assessed the financial capabilities of adolescents. Hence, this large-scale survey among 15-year old students administered by the OECD in 2012 extends the international evidence on financial literacy levels by studying the young, whose financial decisions are arguably most likely to have long-term consequences.

Figure 2 plots mean proficiency levels of more than 29,000 students, who are representative of as much as nine million 15-year olds in the 18 participating countries, ${ }^{22}$ and reveals considerable variation in cross-country financial literacy levels among the young, as well.

As plotted in Fig. 2, 16 out of the 18 countries under review feature financial literacy levels fairly close to the OECD normalized average of 500 points. In this group, the country-specific mean scores range between 466 (Italy) and 541 (Belgium). ${ }^{23}$ Thus, for the vast majority of countries under review, average student proficiency levels are either in Level 2 (400 to less than 475 points) or in Level 3 (475 to less than 550 points). Importantly, the OECD defines Level 2 as an international benchmark for the lower bound of financial capabilities, i.e. marking the threshold between financial literate and financially illiterate individuals. ${ }^{24}$ There are two outliers in this rather homogeneous picture. Students from Shanghai-China perform best with a mean score of 603, Columbian students perform poorest with a mean score of 379. Consequently, the average student from Columbia features Level 1-proficiency (326 to less than 400 points) and, according to the OECD

\footnotetext{
${ }^{22}$ The analysis comprises the OECD economies Australia, Belgium (Flemish Community), Czech Republic, Estonia, France, Israel, Italy, New Zealand, Poland, Slovak Republic, Slovenia, Spain and the U.S. as well as the partner countries Colombia, Croatia, Latvia, Russia and Shanghai-China. Please note that Germany did not participate in this OECD study.

23 Note that in statistical terms, the differences between the country scores reported in Fig. 2 and the OECD average-with the exception of the U.S. - all turn out significant at all conventional levels.

${ }^{24}$ For a detailed description of the different proficiency levels see Lusardi (2015).
} 


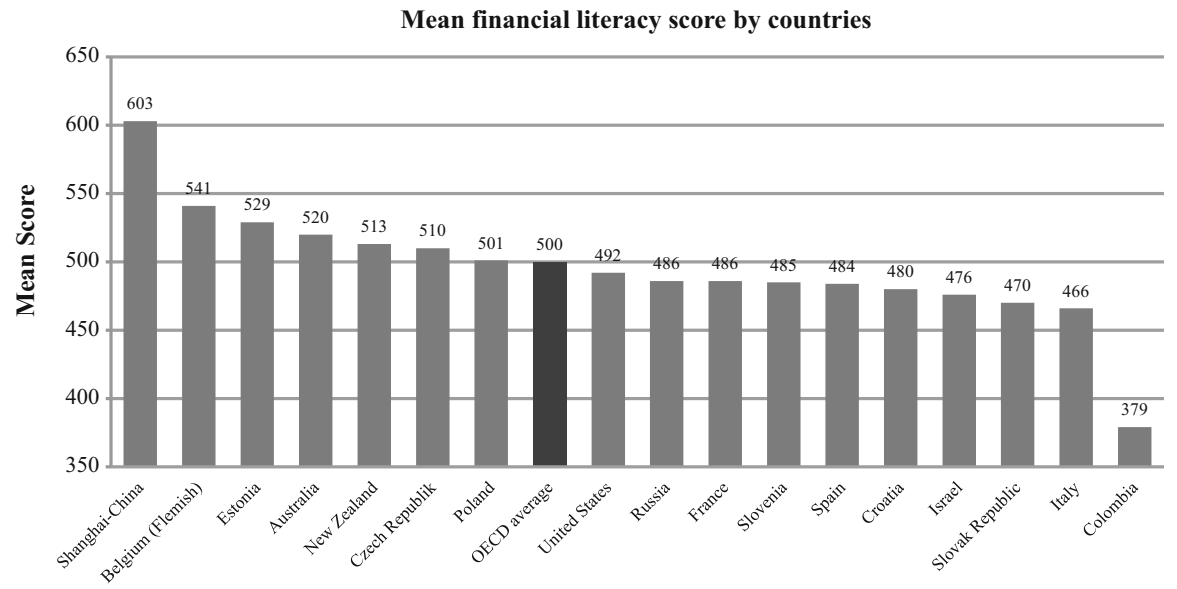

Fig. 2 Mean financial literacy scores, by country (PISA assessment 2012). Notes: This figure plots mean financial literacy proficiency levels of more than 29,000 students representative of as much as nine million 15-year-olds in the OECD economies Australia, Belgium (Flemish Community), Czech Republic, Estonia, France, Israel, Italy, New Zealand, Poland, Slovak Republic, Slovenia, Spain and the U.S. as well as the partner countries Colombia, Croatia, Latvia, Russia and Shanghai-China. See Sect. 3.2 for further details

classification, fails to meet the requirements necessary for basic financially literacy. Regarding the surveyed students' individual proficiency, Lusardi (2015) documents that about $15 \%$ of students perform at or below Level 1-proficiency. ${ }^{25}$

\subsection{Overview of international data on financial literacy}

Table 3 provides the reader with an up-to-date international overview of available surveys that have elicited financial literacy levels among their respective respondents. Panel A lists the available surveys for Germany, Panel B contains European household surveys and Panel C (Panel D) refers to surveys conducted in the U.S. (in other countries).

Besides reporting details on initiators and respondents of the different surveys, Table 3 also provides information about the test-based measurement approach applied (e.g. financial knowledge or cognition). Moreover, the table provides information on whether the Big Three questions were implemented ${ }^{26}$ as well as if the survey has been completed in the past or features ongoing waves. Finally, we indicate whether the data obtained in the survey is publicly available for researchers.

\footnotetext{
25 Within the countries under review, the percentage of financially illiterate students range from $2 \%$ (Shanghai-China) to $56 \%$ (Columbia).

26 A complete list of questions raised in each household survey is available upon request.
} 


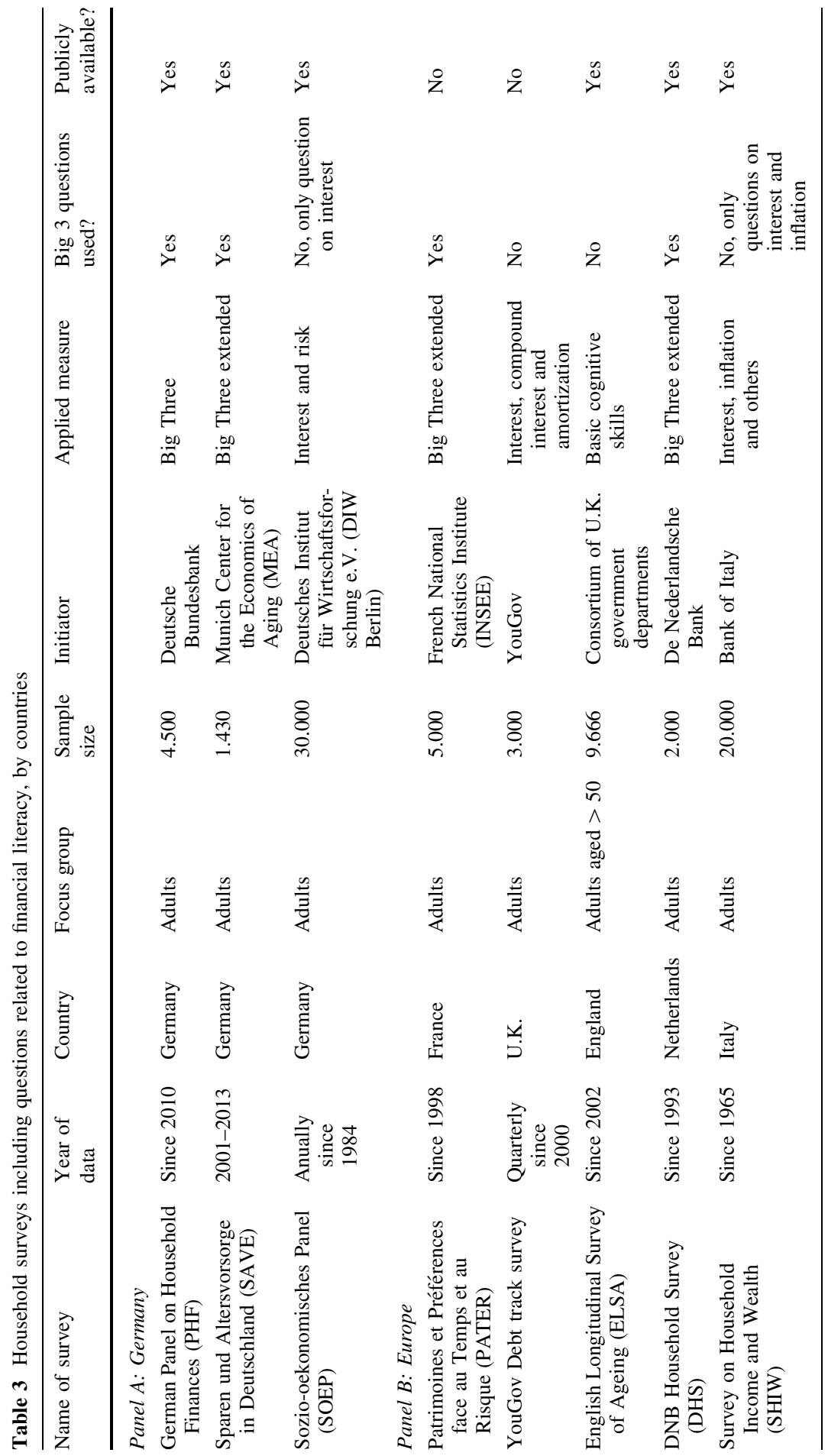




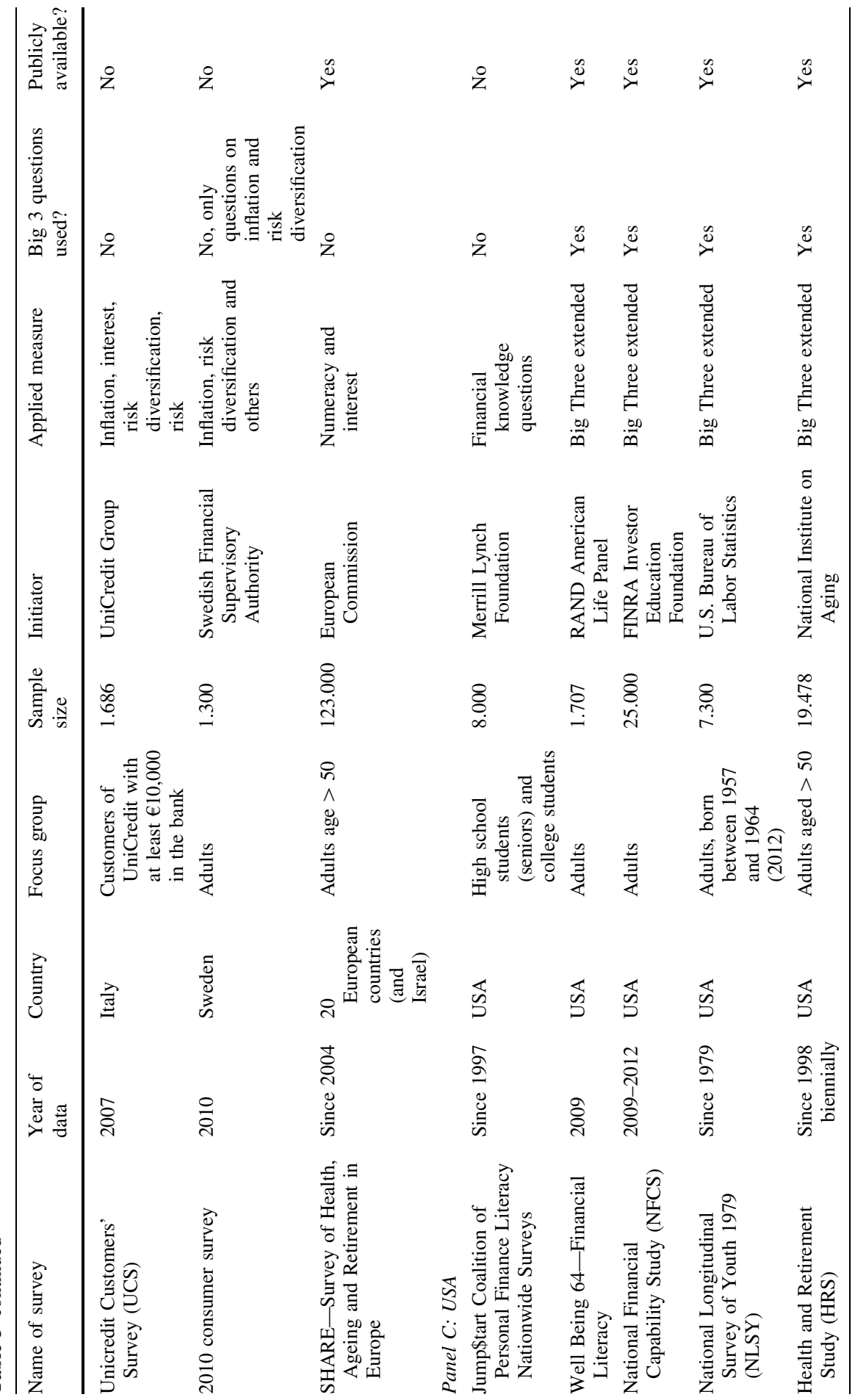




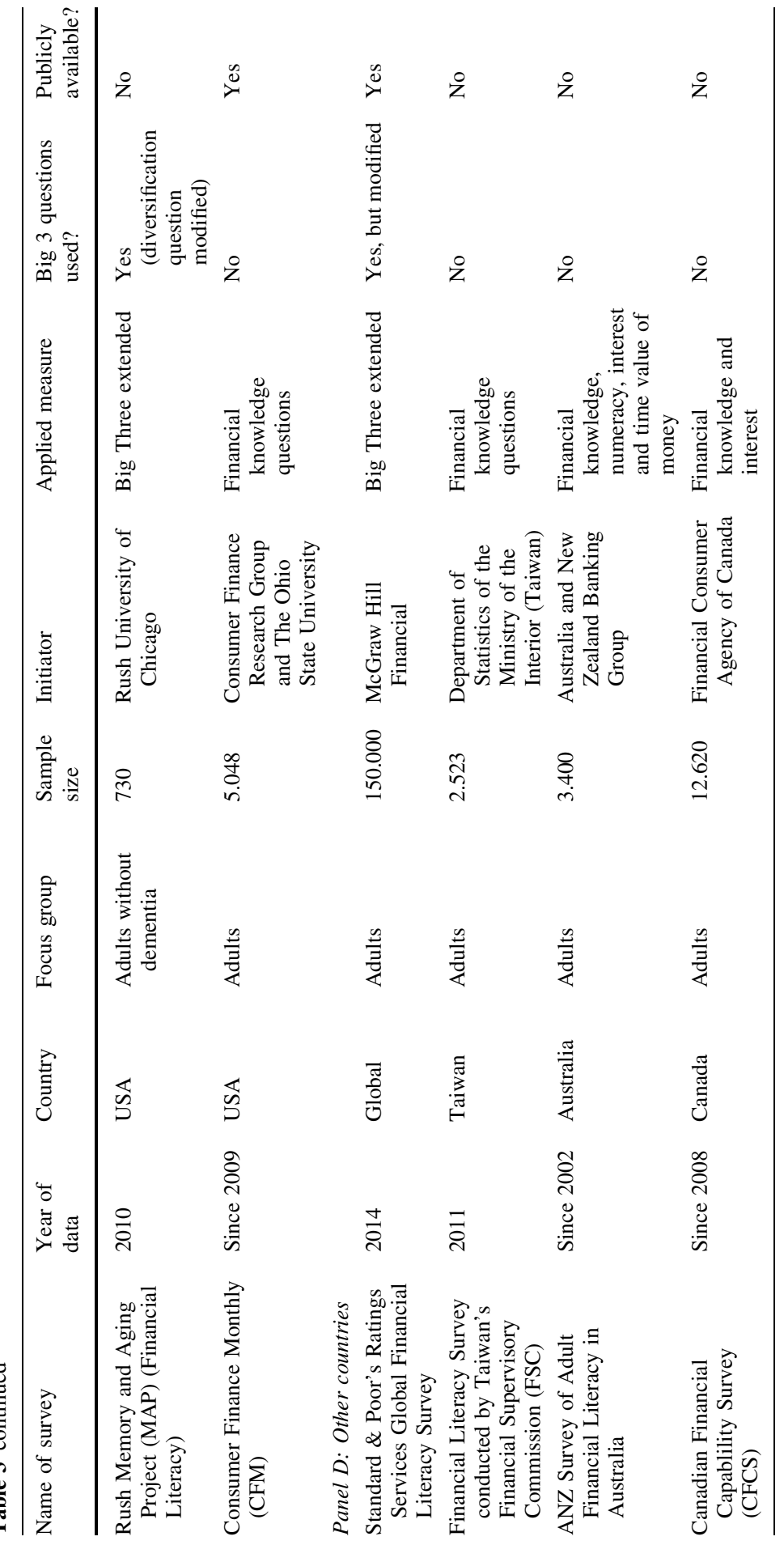




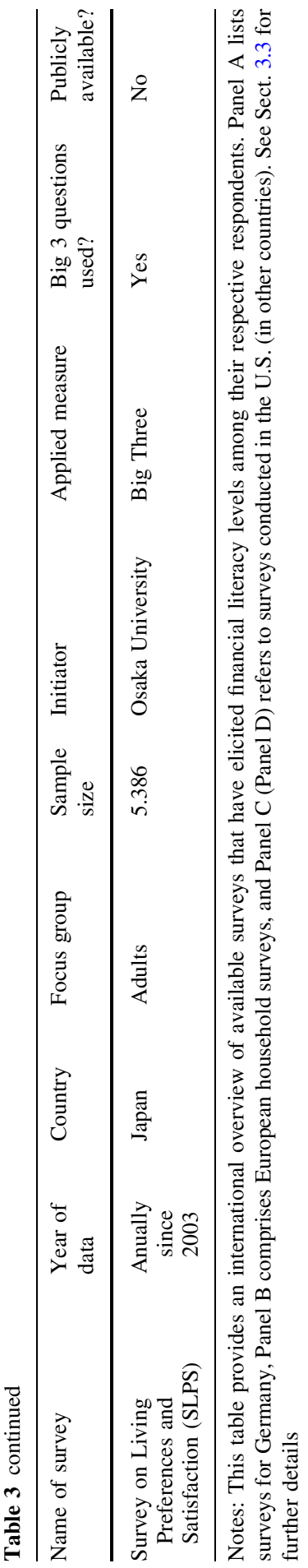

\section{Springer}




\section{Determinants of financial literacy}

After having surveyed the evidence on how financial literacy is distributed across countries, we now turn to the question if there are common determinants related to peoples' individual financial literacy levels.

\subsection{Demographic characteristics}

\subsubsection{Age}

A robust finding across countries is that financial literacy levels are lowest among the young and the old (e.g., Lusardi and Mitchell 2011a, c). Thus, we generally observe a hump-shaped distribution of financial literacy with respect to age. Low literacy among the young might be problematic since this group faces financial decisions that influence their (financial) well-being for decades to come. This is one reason why the OECD included a battery of financial literacy questions in the 2012 PISA assessment for 15-year old students as increasing financial literacy for this group seems to be particularly promising. ${ }^{27}$ Low levels of financial literacy among the old is also problematic as individuals aged 60 and older hold about $50 \%$ of the wealth in the U.S. (Finke et al. 2016). With respect to cognitive changes associated with aging, Gamble et al. (2015) show that a decrease in episodic memory is associated with decreasing abilities in numeracy. In addition, a decrease in semantic memory associated with aging comes along with a decrease in financial knowledge. In consequence, a decrease in cognitive abilities is associated with decreasing financial literacy for the elderly. With respect to the magnitude of the effect of aging, Finke et al. (2016) find that financial literacy scores decline by about $1 \%$ a year for people older than 60. As already mentioned in Sect. 2.3, there is a wide discrepancy between test-based and self-assessed financial literacy for the elderly as this group shows high levels of overconfidence: Gamble et al. (2015) and Finke et al. (2016) show that confidence in financial abilities does not decline with age, making the elderly particularly vulnerable to financial scams and fraud (Deevy et al. 2012). Analyzing the SAVE survey, Bucher-Koenen and Lusardi (2011) underscore this evidence for Germans. Specifically, they also document a hump-shaped distribution of financial literacy levels with respect to respondents' age and find that the least financially literate are individuals aged 65 and above. Admittedly, however, the negative correlation between age and financial literacy documented in the above-mentioned studies might as well be interpreted as a cohort effect: for instance, older people arguably have less investing experience in the pre-401(k) era and the proportion of individuals with higher educational attainment is lower among older cohorts.

We draw on the PHF to investigate if this widely observed age-literacy-pattern continues to hold in a recent survey among German households and find that the hump-shaped relationship between respondents' financial capabilities and their age is indeed corroborated in the PHF data. Specifically, people older than 65 score

\footnotetext{
27 See Sect. 6.1 for a detailed discussion of the costs and benefits of financial education initiatives.
} 
lowest, since only about $47 \%$ of this group are able to answer all Big Three tasks correctly. The second lowest percentage is documented for the group of people that are younger than 30 years old (58\%). Ultimately, the cohort of Germans in their forties are found to be most financially literate (70\%).

\subsubsection{Gender}

Another robust finding across many countries is a gender gap with respect to financial literacy (Lusardi and Mitchell 2009; Lusardi and Tufano 2009, 2015; Lusardi et al. 2010; Hung et al. 2009; Mottola 2013; Bucher-Koenen et al. 2016; Agnew and Harrison 2015, Klapper et al. 2015): men usually score higher on measured financial literacy than women. Two channels have been found to drive this result. On the one hand, women give fewer correct answers in test questions. Lusardi and Mitchell (2014), for instance, document that in the U.S. the fraction of men having all Big Three questions right is $38.3 \%$, while the respective number for women is $22.5 \%$. On the other hand, women seem less confident regarding their financial capabilities as they are more likely to choose the "do not know" category. According to Lusardi and Mitchell (2014) 50.0\% of women in the U.S. indicate that they do not know the answer to at least one of the Big Three questions, while the respective fraction for men is $34.3 \%$. A number of studies try to explain this finding arguing with traditional role models (Hsu 2011) suggesting that women only have an incentive to invest in financial literacy late in their lives (Fonseca et al. 2012), differing levels of confidence (Bucher-Koenen et al. 2016), and diverging interests in financial matters (Brown and Graf 2013). However, none of the approaches can entirely explain the gender gap, thus making the issue a promising avenue for further research.

Again, we use the PHF survey to investigate if the gender gap can be observed for recently collected German data, too. As can been seen in Fig. 3b, we indeed observe a moderate, yet statistically significant gender gap in the PHF survey for Germany. The fraction of participants answering all Big Three questions correctly is $64 \%$ for male and $57 \%$ for female respondents, respectively. Note that previous evidence obtained from the 2009 wave of the SAVE survey (Bucher-Koenen and Lusardi 2011) documented a larger gender gap among German consumers. Specifically, the authors find that almost $60 \%$ of male respondents give correct answers to all Big Three questions as opposed to only roughly $48 \%$ of surveyed females.

\subsubsection{Education}

Furthermore, the majority of contributions to the literature document a positive correlation between formal education and financial literacy (Lusardi and Mitchell 2011c; Christelis et al. 2010; Lusardi 2012). For example, Lusardi and Mitchell (2014) report that in the Netherlands $69.8 \%$ of individuals with a university degree answer all Big Three questions correctly, whereas among the least educated, the respective percentage amounts to only $28.0 \%$. Of course, it is important to analyze whether the positive correlation might be driven by cognitive abilities of respondents rather than by formal education. However, few studies try to 


\section{a}

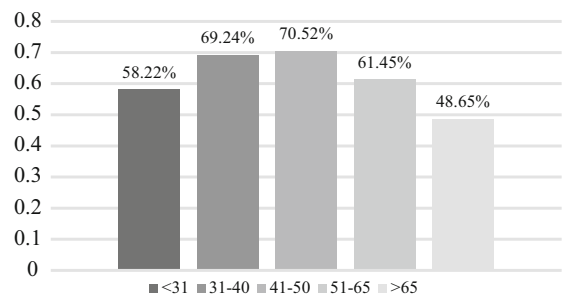

.

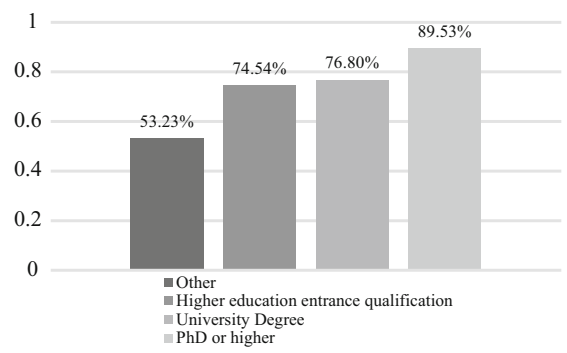

.

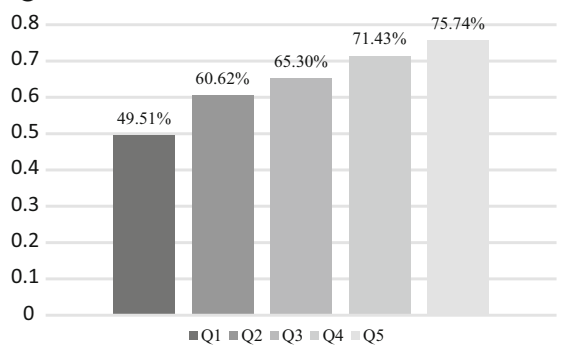

b

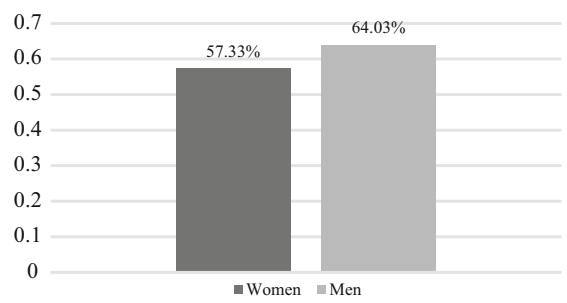

d

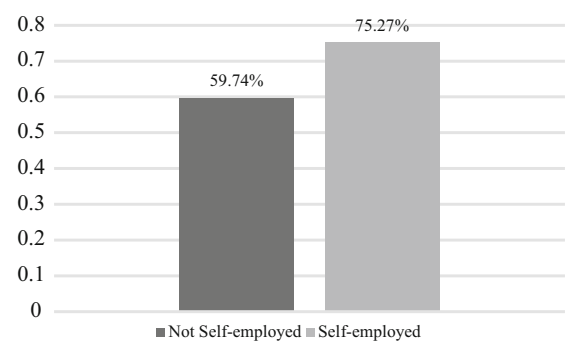

f

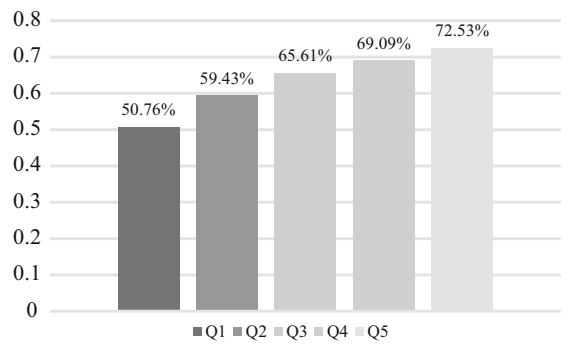

Fig. 3 Percentage providing correct answers to all Big Three questions, by demographic groups. a Financial literacy levels by age. b Financial literacy levels by gender. c Financial literacy levels by educational attainment. d Financial literacy levels by employment status. e Financial literacy levels by income. f Financial literacy levels by wealth. Notes: This figure plots the percentage of individuals surveyed in the first wave of the Panel on Household Finances (PHF) who have answered all Big Three questions correctly, sorted on respondents' demographic characteristics (age, gender, educational attainment, employment status, income, wealth). See Sect. 4.1 for further details

separate cognition from the effect of formal education. Lusardi et al. (2010), e.g., find that formal education is a relevant factor even after controlling for cognitive abilities.

Figure $3 c$ reports the evidence we draw from the PHF data and turns out consistent with the general finding that formal education correlates positively with financial literacy. Among those respondents featuring the highest educational attainment, an overwhelming majority of almost $90 \%$ manage to answer all Big Three questions correctly, whereas for the group of least educated individuals, the respective fraction comes to only $53 \% .{ }^{28}$ At this, the novel data we analyze broadly

\footnotetext{
${ }^{28}$ Bannier and Neubert (2016a), drawing on the SAVE data, show that the effect of formal education is strongest for women.
} 
confirm earlier evidence for Germany provided by Bucher-Koenen and Lusardi (2011) who also document a positive relationship between education and financial literacy based on the SAVE survey.

\subsubsection{Professional status, income, and wealth}

Furthermore, the PHF survey collects information about participants' professional status. Figure $3 \mathrm{~d}$ shows that the self-employed are significantly more likely to answer the Big Three questions correctly, a finding which has also been documented in Bucher-Koenen and Lusardi (2011). Finally, a number of contributions have found a positive association between individuals' income and wealth levels and their levels of financial literacy (e.g., Hung et al. 2009; Lusardi and Tufano 2015; Lusardi and Mitchell 2011c; Klapper et al. 2015). As can be seen in Fig. 3e, f, we again confirm this finding for the PHF survey. With respect to income, $76 \%$ of the individuals in the highest income quintile managed to answer all Big Three questions correctly. The respective fraction for the lowest income quintile turns out significantly lower (50\%). We find a similar result with respect to wealth; $73 \%$ of the individuals in the highest wealth quintile answer all Big Three questions correctly, whereas the respective fraction for the lowest wealth quintile is $51 \% .^{29}$

\subsection{Additional patterns}

Recently, some contributions have examined the impact of peoples' financial socialization on their financial literacy levels. For example, Grohmann et al. (2015) identify three potential channels of financial socialization: family, school and work and find that two of the three channels, i.e. family and school, indeed have a positive impact on the financial literacy of the adult subjects in their study. Regarding peoples' family background, Lusardi et al. (2010) analyze financial literacy levels of young adults and relate them to the financial literacy levels observed for other members of the households in which they were raised. The authors document a positive correlation between financial literacy levels documented for the young adults and both financial literacy scores and educational attainment of their parents. ${ }^{30}$ Moreover, financial behaviors of the respondents' parents and their educational background are shown to independently influence financial literacy levels measured for their children. Finally, in a related study on the role of financial

\footnotetext{
${ }^{29}$ Note, however, that the literature has produced mixed results as to whether causality runs from wealth to financial literacy or rather the other way round. While Monticone (2010) documents that wealth has a positive (albeit small) effect on the degree of financial knowledge, wealth has been shown to be endogenous in other contributions. Van Rooij et al. (2012), e.g., provide evidence of a strong positive association between financial literacy and financial wealth and argue that it is financial literacy, which facilitates wealth accumulation. In a related study, Lusardi et al. (2013) develop a life-cycle model with endogenous financial knowledge accumulation and conclude that it explains a large proportion of wealth inequality.

30 The effect of childhood experience on financial behavior is also analyzed in Bucciol and Veronesi (2014) and Webley and Nyhus (2006, 2013).
} 
socialization, Lachance (2014) finds that even the educational attainment of respondents' neighbors on average impacts their financial literacy levels.

\section{The role of financial literacy for financial behavior}

\subsection{Endogeneity concerns}

\subsubsection{Sources of endogeneity}

As mentioned above, the relevance of financial literacy crucially depends on its impact with regard to sound financial behavior. Consequently, a voluminous literature analyzes the question whether high levels of financial literacy trigger superior financial decision making. As we will review shortly, the majority of papers document a positive correlation between measures of financial literacy and sound financial behavior in various domains. ${ }^{31}$ However, absent true randomized control experiments allowing for direct causal inference, the effect of financial literacy on the quality of individual financial decisions is difficult to pin down. Since most evidence on the impact of financial literacy stems from non-experimental research, endogeneity presents a pervasive issue which should be considered carefully when examining the role of financial literacy for financial outcomes. While endogeneity does not rule out the possibility that financial literacy improves individuals' financial decision making per se, it complicates interpreting the magnitudes of the estimated effects as they are almost surely upwardly biased in magnitude (Hastings et al. 2013).

What causes endogeneity and how does it impact inference? Omitted variables are one of the three sources of endogeneity and refer to those explanatory variables that should be included in the model but in fact are not. If the positive correlation between financial literacy and good financial decisions observed in a given setting likely owes to some underlying third factor which contributes to both higher levels of financial literacy and better financial outcomes, endogeneity enters the model by way of one or more omitted variables. In statistical terms, the inability to explicitly include these determinants in the regression equation means that instead of appearing among the explanatory variables, the impact of these omitted variables appears in the error term, thus distorting estimators and making reliable inference virtually impossible.

Indeed, financial literacy might not be distributed randomly and those individuals exhibiting high levels of financial literacy might share certain characteristics like superior numerical abilities, intelligence, motivation to deal with personal finances, or patience. The literature documents several instances of such hard-to-capture

\footnotetext{
31 Intuitively, we have to agree on a definition of sound financial behavior in order to be able to interpret this relationship. Depending on the context, this proves a nontrivial task. While investing in the stock market, for instance, is generally considered smart, individuals with extreme levels of risk aversion or short-term liquidity needs might not be well-advised to do so. In what follows, however, we adopt the literature consensus and thus, e.g., classify index fund investments (as opposed to investments in actively managed mutual funds) as sound financial decisions.
} 
factors likely to influence both financial literacy and financial behavior. Meier and Sprenger (2010) show that those who voluntarily participate in financial education programs are more future-oriented. Hastings and Mitchell (2011) find that those who show patience in an experiment also have a higher propensity to save additional amounts for retirement in their pension accounts. In the same vein, Bucher-Koenen and Lusardi (2011) hypothesize that there might exist an omitted variable bias stemming from missing information on individuals' ability or motivation to deal with financial matters.

Additionally, a positive correlation between financial literacy and sound financial decision making could stem from reverse causality. Specifically, does financial literacy improve financial behavior or does being involved in certain financial activities instead lead to greater financial literacy? Again, the literature provides a number of examples of potential endogeneity due to a reverse causation channel. Disney et al. (2015) investigate the effect of financial literacy on the decision to seek credit counseling and argue that financial literacy may develop endogenously with the receipt of credit counseling. Bucher-Koenen and Lusardi (2011) hypothesize that individuals with higher levels of financial literacy might better recognize the need and the financial benefits of saving for retirement and thus be more inclined to enroll in a savings plan. They acknowledge, however, that it may as well be retirement planning which affects financial literacy rather than the other way around: Those who have planned for retirement have acquired some level of financial literacy simply by virtue of their savings plan participation. Likewise, the finding of Hilgert et al. (2003) that most individuals cite personal experience as the most important source of their financial learning suggests that some element of reverse causality is likely.

Finally, endogeneity may also arise from measurement error when it comes to the financial literacy variables, e.g. the possibility that answers to test-based financial literacy measures might not measure "true" financial knowledge. As mentioned above, Lusardi and Mitchell (2009), for instance, show that the Big Three are sensitive to framing, i.e. implying that some answers judged to be "correct" are likely attributable to guessing rather than skill.

\subsubsection{Towards a causal interpretation of the effect of financial literacy on financial behavior}

The standard approach to address endogeneity is finding an instrumental variable (IV) for the endogenous regressor and use this IV in a two-stage least squares (2SLS) regression in order to produce consistent parameter estimates. Generally, a clear understanding of the economics governing the question of interest is key to identifying a valid instrument. A good example of instrument choice is given in van Rooij et al. (2011b) who document a positive relationship between stock market participation and financial literacy which is not only consistent with financially savvy investors having knowledge about expected excess returns of stocks, but also with shareholders learning from their investment experience. ${ }^{32}$ To establish

\footnotetext{
32 For further examples of particularly strong instruments for financial literacy, see Lusardi and Mitchell (2014).
} 
causality, the authors resort to IV estimation and instrument financial literacy with information regarding the personal finances of their siblings and parents, respectively. Specifically, they asked respondents whether the financial situation of their oldest sibling is either worse or the same or better than their own financial situation and also collected information on how they assess the level of financial knowledge of their parents. Why do these items make particularly good IVs? For one, these instruments for financial literacy are exogenous with respect to respondents' stock market participation since, arguably, the financial experience of others is beyond their control. At the same time, however, respondents likely learn from their families, thereby increasing their own literacy. ${ }^{33}$ Hence, the instruments affect the outcome (the respondent's propensity to participate in the stock market) only via their effect on the endogenous variable (the respondent's financial literacy level), i.e. satisfy both the relevance and the exclusion condition required to hold for a valid IV.

Observational studies using carefully chosen IVs are sometimes regarded as being equivalent to quasi experiments regarding their power to support causal claims (Angrist and Krueger 2001). However, a few general comments are in order when discussing the IV regression approach. First, since the error term is unobservable, one cannot empirically test the exclusion condition, i.e. whether or not an instrument is correlated with the regression error term. Consequently, there is no way to statistically ensure that an endogeneity problem has been solved. Moreover, Roberts and Whited (2013) stress that truly exogenous instruments are difficult to find and, in particular, that it should be rigorous economic arguments rather than formal falsification tests that eventually decide over the instrument's validity.

\subsubsection{Is there an endogeneity bias in the effect of financial literacy on financial behavior?}

Evidence on the question of whether or not there is an endogeneity bias caused by omitted variables, reverse causality, or measurement error in studies examining links between measured financial literacy and financial behavior is rather inconsistent. In their review of 11 studies estimating both OLS and IV specifications from their data, Lusardi and Mitchell (2014) find that the IV financial literacy estimates always prove to be larger than the ordinary least squares estimates and conclude that, if anything, non-instrumented estimates of financial literacy underestimate the true effect. This evidence is a strong case for substantial measurement error biasing the OLS estimates, since the magnitude of the coefficients should be upwardly biased if omitted variables and reverse causality were the only sources of endogeneity. By contrast, Fernandes et al. (2014), who conduct a meta-analysis of the relationship between financial literacy and financial

\footnotetext{
33 van Rooij et al. (2011b) argue that the negative correlation between respondents' financial literacy levels and the financial condition of their siblings and the financial knowledge of their parents, respectively, support the notion of a learning channel rather than the existence of family fixed effects. Note that the underlying assumption is that respondents learn from the negative experience of their family members.
} 
outcomes and-unlike Lusardi and Mitchell (2014)—consider standardized coefficients, find significantly smaller effects for 24 studies using both instrumental variables and OLS estimation lacking those controls. They conjecture that noninstrumented regression models in fact overestimate the effect of financial literacy, which reflects endogeneity bias predominantly owing to omitted variables and reverse causality in the OLS designs. Additionally, they test the proposition that designs using instruments for financial literacy and 2SLS are similar to quasi experiments with regards to their ability to support causal inferences-in which case effect sizes should be comparable to what one finds in intervention studies that manipulate financial literacy by means of providing financial education to the treatment group. However, rejecting this claim, they find that intervention studies on average show much smaller effects than econometric studies with instrumental variables and question the validity of instruments used for financial literacy in the studies they review in their meta-analysis. Based on these findings, the authors conclude that past work supporting a causal role for financial literacy might need revisiting on methodological grounds.

Taken together, both the relevance of endogeneity concerns and the tools to remedy potential endogeneity bias are discussed rather controversially in the literature. Outside of controlled experiments, there is no way to ensure that endogeneity problems are eliminated or sufficiently mitigated to allow for reliable causal inferences. Thus, addressing endogeneity concerns by way of IVs should always rest on the strength of the researcher's arguments supporting the identification strategy.

In what follows, we survey the literature on the impact of financial literacy on financial decision making in various different domains. While we will not explicitly discuss potential endogeneity concerns in the contributions under review, the reader should keep in mind that these issues might still apply.

\subsection{Savings and investment decisions}

\subsubsection{Retirement planning}

With respect to investment and savings decisions, arguably most research has been conducted on whether financial sophistication has a positive impact on retirement planning (e.g., Lusardi and Mitchell 2007, 2008; van Rooij et al. 2011a). Analyzing German survey data, Bucher-Koenen and Lusardi (2011) provide evidence for a strong correlation between financial literacy and retirement planning. Regarding the Big Three, the authors show that about $70 \%$ of the households who have planned for retirement give correct answers to all Big Three questions, whereas the respective fraction is only $54 \%$ for non-planners. Studies analyzing financial behavior in the U.S. also find that individuals with low levels of financial literacy are less likely to plan for their retirement (e.g., Lusardi and Mitchell 2007, 2011b). In a recent study, Clark et al. (2015), using a dataset that links administrative data on investment success with financial literacy, document a positive relationship between individuals' financial literacy and their propensity to participate in a 401(k) plan as well as the profitability of the respective investments. A related strand of literature has also documented a positive relation between financial literacy and savings behavior (e.g., 
Lusardi and Mitchell 2011c; Chan and Stevens 2008; Behrman et al. 2012), i.e. providing additional evidence that financially literate individuals exhibit a greater tendency to plan ahead.

\subsubsection{Stock market participation}

Another robust finding in the literature is a positive correlation between stock market participation and financial literacy (e.g., Kimball and Shumway 2006; Christelis et al. 2010; van Rooij et al. 2011b; Balloch et al. 2015; Clark et al. 2015). Specifically, van Rooij et al. (2011b) document that financial sophistication is positively related to stock market participation of retail investors in the Netherlands. Analyzing U.S. survey data, Yoong (2011) confirms that financially sophisticated individuals are more likely to hold stocks and mutual funds. In a related study among retail investors in the U.S., Balloch et al. (2015) find that, besides trust, stock market literacy positively correlates with their likelihood of stock market participation. In addition, they show a positive association between financial sophistication and the conditional magnitude of investing in stocks for those households who do hold stocks in their portfolios. Finally, Jappelli and Padula (2015) present an intertemporal choice model in which individuals can invest in financial literacy. Drawing on cross-country data, the authors find empirical support for the model's main prediction, i.e. that stock market participation and financial literacy are positively correlated.

\subsubsection{Investment choices}

A related strand of literature analyzes the association between financial literacy and trading behavior (e.g., Feng and Seasholes 2005; Bilias et al. 2010; Hoffmann et al. 2013; Bucher-Koenen and Ziegelmeyer 2014; Guiso and Viviano 2015) and the corresponding studies generally document a positive impact of financial literacy as financially sophisticated investors tend to commit less investment mistakes. ${ }^{34}$ In a recent contribution, Bucher-Koenen and Ziegelmeyer (2014) use the financial crisis as a natural experiment to examine individual investors' ability to cope with sudden economic shocks and document that low literate households are significantly more likely to sell off assets that have lost in value, thereby making paper losses permanent. Shunning stock markets altogether is also associated with a decrease in expected returns on investments (Bucher-Koenen and Ziegelmeyer 2014). Other research in the field has documented that financial literacy is associated with smart choices when it comes to the selection of financial products. Müller and Weber (2010), for instance, investigate the role of financial literacy for mutual fund selection and show that financially sophisticated German retail investors pay lower front-end loads, are less biased in their past return estimates, and are more likely to correctly assess the risk profile of their fund investments. In a related laboratory study, Choi et al. (2009) show that many U.S. investors-even those with

\footnotetext{
${ }^{34}$ In a related study, Koestner et al. (2017) identify investment experience as another potential channel to mitigate investment mistakes.
} 
high self-assessed financial literacy levels-fail to choose a fee minimizing portfolio even in a setting where fees are the only relevant distinguishing characteristic of the investments and differences in fees are considerable. Moreover, a number of studies has documented a positive link between financial literacy and portfolio diversification: highly literate investors tend to manage their risks significantly better than the group of low literate individuals (e.g., Calvet et al. 2007; Goetzmann and Kumar 2008; Guiso and Jappelli 2008; von Gaudecker 2015; Clark et al. 2015).

\subsubsection{Investment performance}

The literature also documents a positive link between financial literacy and sound investment decisions. Calvet et al. $(2007,2009)$ show for investors in Sweden a positive correlation between financial sophistication and account performance and conclude that richer and financially more sophisticated individuals invest more efficiently. Likewise, Clark et al. (2015) document a positive correlation between financial sophistication and excess stock returns among U.S. individuals, while von Gaudecker (2015) finds that this group of retail investors is more likely to hold welldiversified portfolios. Deuflhard et al. (2014) analyze interest rate levels for savings accounts of Dutch consumers. They find that financial literacy is positively associated with higher returns on these accounts. By contrast, Bodnaruk and Simonov (2015) provide evidence against the common finding of a positive relation between financial sophistication and investment performance. In particular, the authors have access to the private portfolios of Swedish mutual fund managersarguably highly sophisticated market participants—and show that this unique group of individual investors neither outperform, nor diversify their risks more effectively as compared to similar investors in terms of age, gender, education, income, and wealth.

\subsubsection{Additional evidence}

Finally, the literature documents a positive role of financial capabilities in a variety of other domains. For example, Shen et al. (2016) document for Taiwan that individuals with higher levels of financial literacy are less likely to engage in financial disputes. Banks et al. (2015) find for the U.K. that financial literacy and numeracy are significantly positively related to individuals' propensity to shop around for an annuity when receiving funds from their defined contribution pensions. In an early contribution to the literature, Hilgert et al. (2003) find a strong correlation between financial sophistication and day-to-day financial management skills such as cash-flow and credit management. Finally, de Bassa Scheresberg (2013) documents a positive relation between consumers' financial literacy and their individual likelihood to hold precautionary savings. 


\subsection{Financing decisions}

\subsubsection{High-cost borrowing}

Compared to the large body of literature linking financial literacy to saving and investment decisions, evidence on the role of consumers' financial capabilities for their financing behavior is scarce. Not surprisingly, the literature typically documents a negative correlation between financial literacy and mistakes in financing decisions: the less financially literate individuals are, the more likely they are to make poor financing decisions. Most prominently, there is solid evidence that low levels of financial literacy are associated with high-cost borrowing and suboptimal mortgage choices (e.g., Moore 2003; Lusardi and Tufano 2015; Lusardi and de Bassa Scheresberg 2013; Disney and Gathergood 2013). Lusardi and Tufano (2015) show for the U.S. that individuals exhibiting low levels of financial literacy use high-cost borrowing and pay higher transaction costs and fees. Lusardi and de Bassa Scheresberg (2013) also examine high-cost borrowing in the U.S., including payday loans, pawn shops and auto title insurance. They also confirm that low literate individuals are substantially exposed to high-cost methods of borrowing. Disney and Gathergood (2013) confirm this finding for the U.K. by showing that low levels of financial literacy are associated with an excessive use of high-cost credit like payday loans or mail order catalogue debt.

\subsubsection{Costly credit card practices and excessive debt accumulation}

Other recent studies document that individuals with low levels of financial literacy are significantly less likely to use their credit cards efficiently (e.g., Lusardi and Tufano 2015; Mottola 2013; Allgood and Walstad 2013). Analyzing U.S. adults, Allgood and Walstad (2013) find a robust negative relation between financial literacy and costly credit card practices. The authors also show that the influence of self-assessed financial literacy on costly credit card practices is greater than that of test-based financial literacy, providing evidence that the two concepts are distinct from each other. ${ }^{35}$ Analyzing the same dataset, Mottola (2013) also confirms that the financially literate respondents are less often found to exhibit costly credit card behaviors such as being charged a late fee for late payment or not paying down credit card debt in full. In addition, some studies show that a lack of financial literacy is associated with excessive debt accumulation (e.g., Stango and Zinman 2009; Lusardi and Tufano 2015). Analyzing U.S. consumers, Lusardi and Tufano (2015) show that the least sophisticated with respect to debt literacy are exposed to excessive debt loads and the authors also find that this group is not able to judge their debt positions. Finally, Gerardi et al. (2013) find that numerical abilities - a skill set which is positively associated with financial sophistication-are strongly negatively correlated with mortgage defaults.

\footnotetext{
35 See Sect. 2.3 for a detailed discussion of this issue.
} 


\section{Towards improved financial decision making}

\subsection{Financial education}

\subsubsection{The case for financial education}

The arguments in favor of financial education are straightforward. Common sense suggests that introducing financial education initiatives will increase financial literacy, and improved financial literacy, in turn, relates to better financial decision making (Alsemgeest 2015). Accordingly, governments around the world have identified financial education as an intuitive remedy in order to help individuals mastering their personal financial affairs (Fernandes et al. 2014; Willis 2011). For example, policy makers in the U.S. have embraced financial literacy as a means to avoid poor financial decision making and launched a number of financial education initiatives in the wake of the financial crisis. Most prominently, the Office for Financial Education, a subdivision of the Consumer Financial Protection Bureau (CFPB) which was established in the wake of the financial crisis, has an explicit mandate to develop a strategy to increase the financial literacy of U.S. consumers as well as to make recommendations for the launch of programs to improve financial education outcomes.

Although great effort is put in financial education, the question whether educating individuals in the financial domain is beneficial remains controversial both from a theoretical and an empirical perspective. Accordingly, Willis $(2008,2011)$ provides a number of arguments against financial education. First, she questions whether financial literacy programs can improve consumers' financial knowledge to an extent that truly qualifies them for the complexity of novel financial products. In particular, she suggests that "the predicate belief in the effectiveness of financial literacy education lacks empirical support. Moreover, the belief is implausible, given the velocity of change in the financial marketplace, the gulf between current consumer skills and those needed to understand today's complex nonstandardized financial products, the persistence of biases in financial decision making, and the disparity between educators and financial-services firms in resources with which to reach consumers." (p. 197). Second, she is concerned that individuals' perceived confidence might increase due to financial education while their actual abilities have not significantly improved which might lead to even poorer financial decision making. Third, she suspects financial education to weaken the position of consumers as related initiatives might come along with a "regulation-through-education model" which blames individuals for bad financial outcomes and thus prevents effective market regulation (Willis 2008). Finally, she pledges for a division of labor as consumers usually do not serve as their own doctors and lawyers and, following this notion, should not serve as their own financial experts, either. 


\subsubsection{Selected financial education initiatives and the costs of financial education}

Although the systematic conceptualization of financial literacy is a rather recent development, financial education programs have a long tradition, at least in the U.S. These programs have been initiated by either policymakers, the financial services industry, employees, or nonprofit organizations. ${ }^{36}$ Hastings et al. (2013) report that financial education interventions in the U.S. date back as long as to the 1950s. Tang and Peter (2015) document that the number of U.S. states in which a personal finance course is required for high school graduation has risen from 13 in 2009 to 17 in 2013, thus highlighting the increased relevance of the topic. The authors also report that the financial services industry is very active in encouraging financial education as, e.g., $98 \%$ of U.S. community banks sponsor financial literacy programs and $72 \%$ provide an individual program for customers.

Table 4 provides a list of selected financial education programs and we include this list for scholars interested in researching specific programs with respect to their effectiveness. We compiled the list of initiatives by searching the literature on financial education programs and by searching the web for respective keywords. Since we cannot do justice to the large number of financial education programs initiated around the world, we focus on initiatives carried out in German-speaking countries (Panel A) and extend this sample by selected programs in other countries arguably most relevant for previous research on financial literacy (Panel B).

As can be inferred from the table, the initiatives differ in terms of the initiator (e.g. banks, endowments, supranational organizations), the target group (e.g. adults, teenagers, low-income individuals), the educational approach (e.g. in-class teaching or online courses), the intensity of the intervention, and, finally, whether the effectiveness of the respective program has received an academic evaluation.

In what follows, we will review the literature assessing the effectiveness of the different financial education programs. Clearly, the implementation of such programs comes at a cost and, furthermore, their specific content might be biased by initiators' incentives as well as political agendas. With regard to costs, Fernandes et al. (2014) highlight that educational interventions are not only associated with real costs but might create much larger opportunity costs. Taking high school education as an example, introducing personal finance courses is most likely associated with replacing other important elective courses. With respect to politically differing views of the world, left-wing governments might want to implement other curricula as opposed to right-wing or market-liberal governments. As far as the financial education initiatives of the financial services industry are concerned, these programs will most likely omit important topics like, e.g., fees. So, these programs would hardly teach participants to buy index funds instead of actively managed funds although refraining from actively managed funds is generally regarded as good financial behavior.

\footnotetext{
$\overline{36}$ Collins (2012) surveys the role of nonprofit providers in financial education.
} 


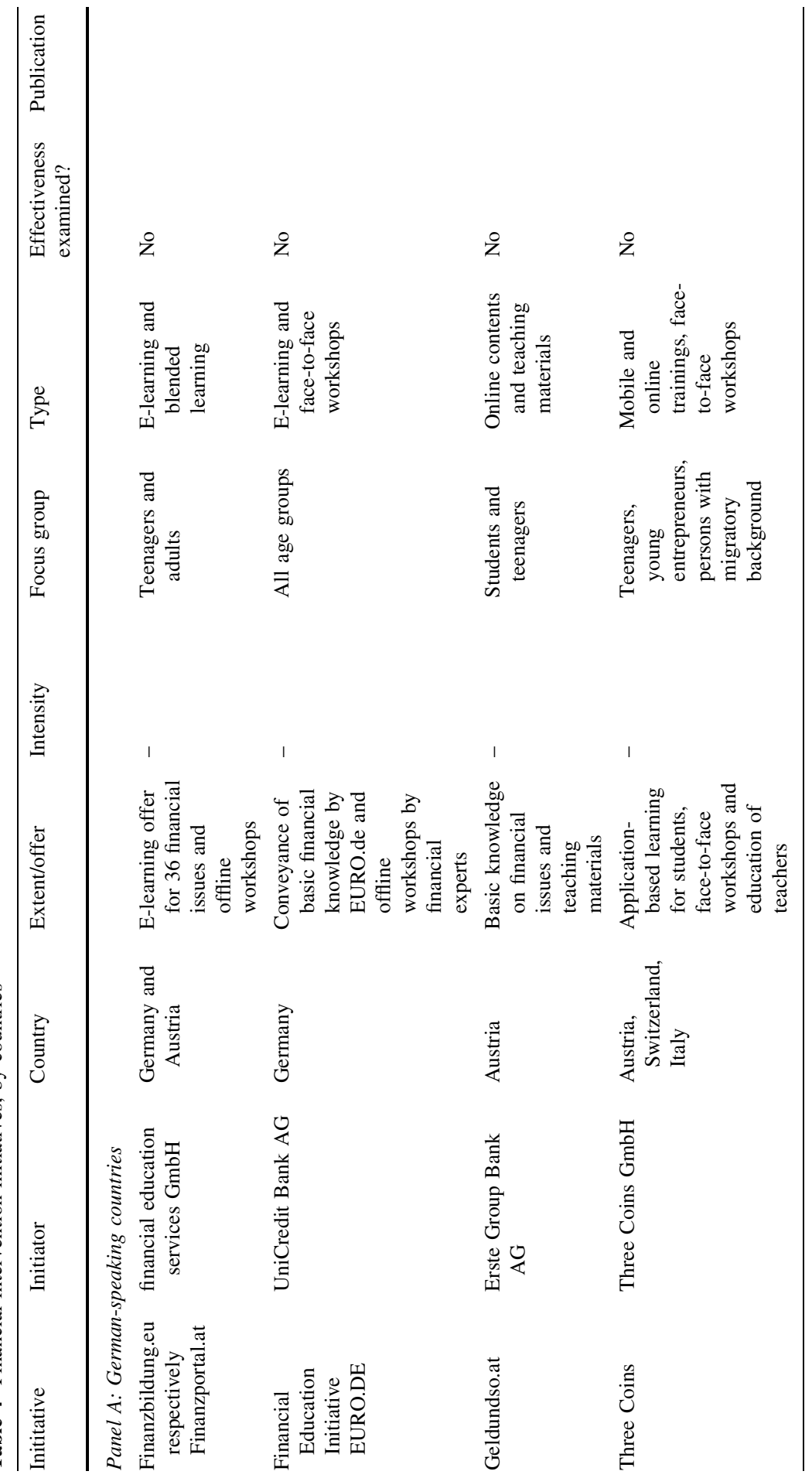




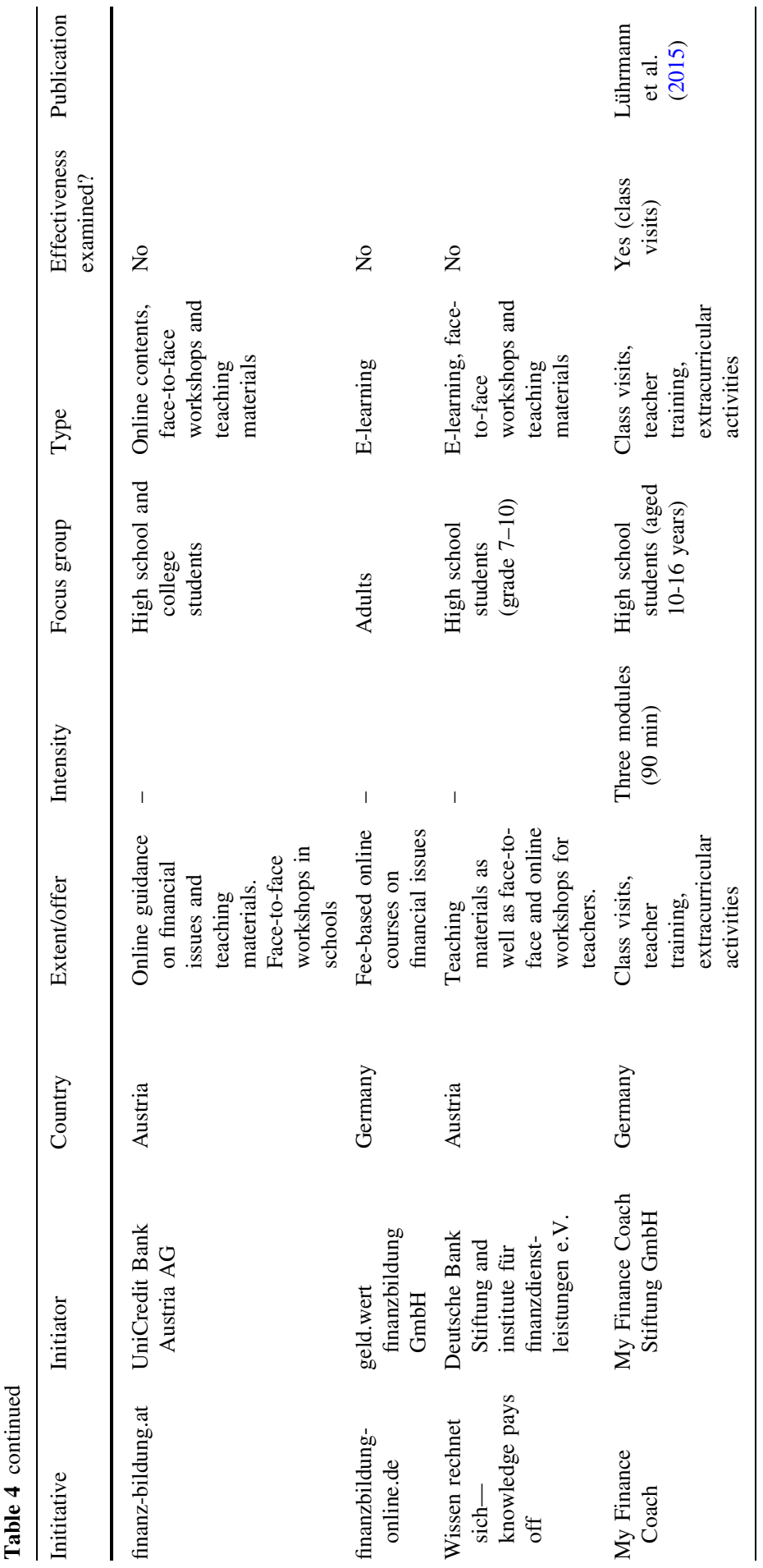




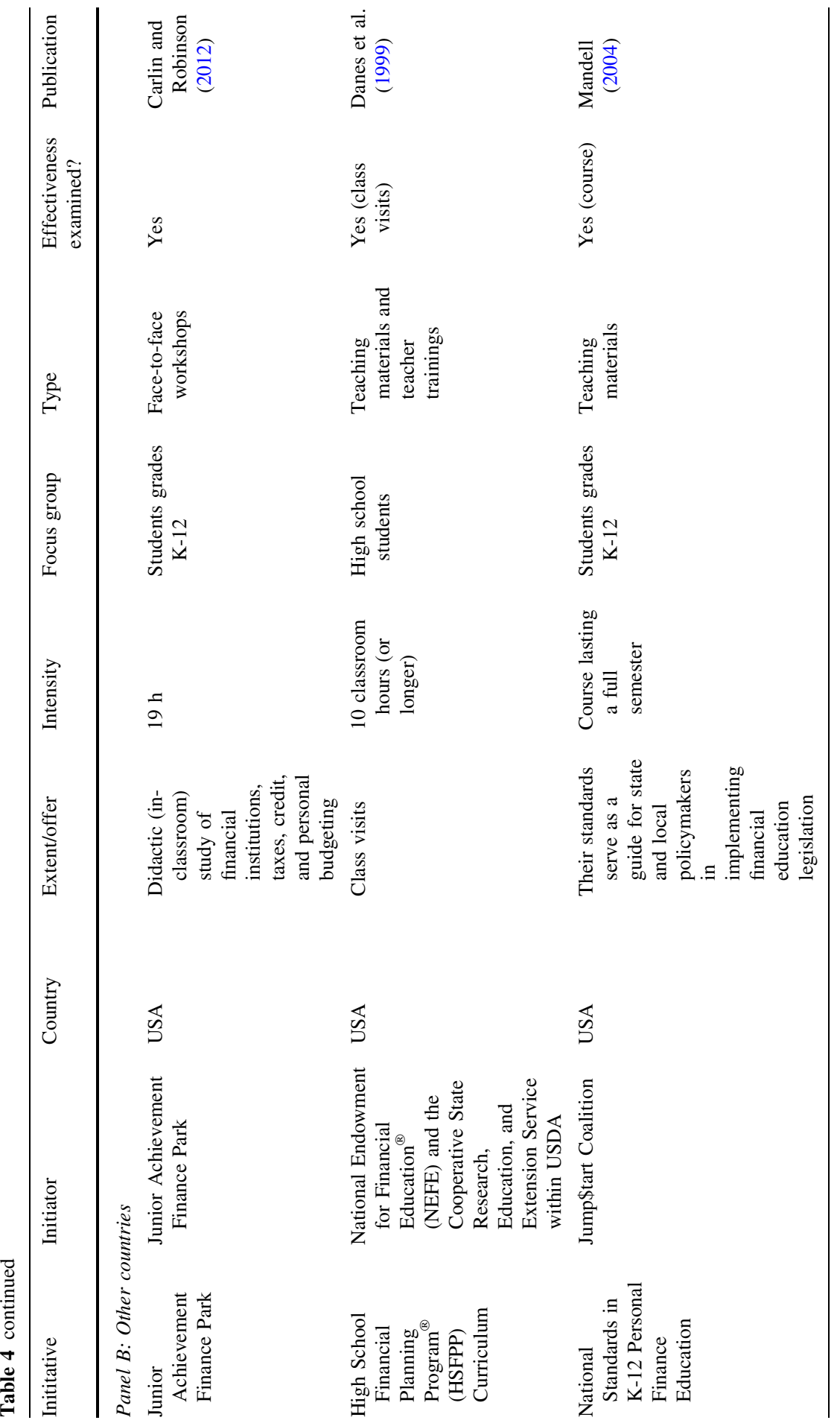




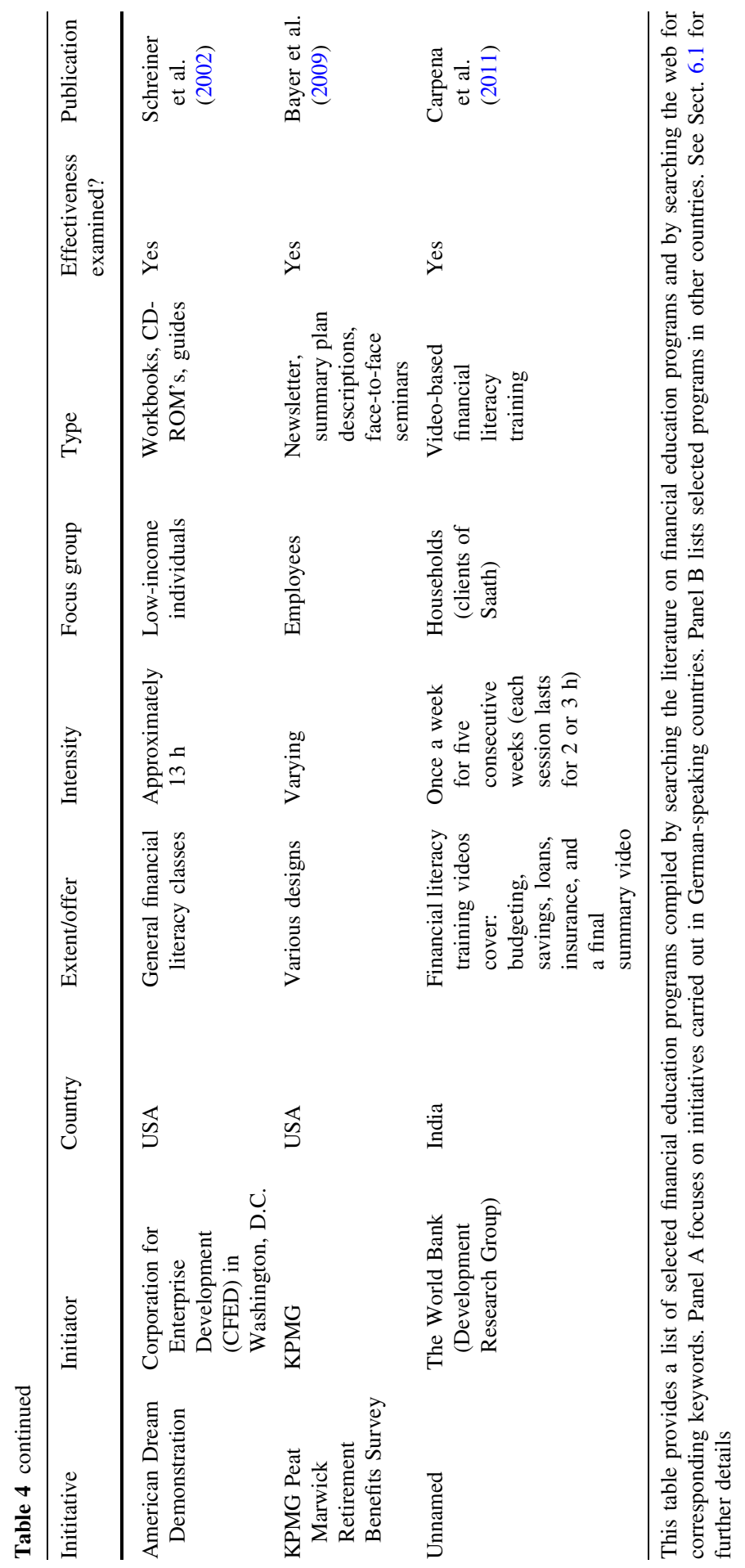




\subsubsection{The effectiveness of financial education programs}

A voluminous literature evaluates the association of financial education and testbased financial literacy (e.g., Mandell 2008; Walstad et al. 2010; Heinberg et al. 2010; Lührmann et al. 2015) as well as financial behavior (e.g., Bernheim et al. 2001; Servon and Kaestner 2008; Clark et al. 2015; Lührmann et al. 2015). The literature usually approaches the topic as follows: A particular financial education intervention is analyzed with respect to its impact on measured financial literacy and-in most assessments-on financial behavior. One way to elicit potential changes in financial literacy levels involves measuring test-based literacy scores prior to educating subjects about the financial matters of interest and at some point in time after they have received the respective manipulation (e.g., Walstad et al. 2010). Alternatively, the financial literacy scores of a treatment and a control group are contrasted after a given educational intervention (e.g., Lührmann et al. 2015). The effectiveness of the programs is usually measured by tracking self-reported financial behavior of the participants which is elicited by means of a questionnaire (e.g., Lusardi and Mitchell 2007; Bell et al. 2009; Lührmann et al. 2015).

Fernandes et al. (2014) have recently conducted a meta-analysis in which they include the entire universe of published and unpublished studies on financial education interventions and standardize effect sizes reported in the original studies when aggregating the respective findings. Thus, the conclusions derived from this meta-analysis are arguably less prone to criticism on methodological grounds. The authors evaluate as much as 90 studies in which a financial education intervention has been examined and conclude that, on aggregate, financial education interventions explain no more than $0.1 \%$ of the variance in financial behavior. Moreover, they confirm prior findings showing that the already small effects of financial education initiatives tend to decline over time. Specifically, they show that even large interventions have only little impact when financial decisions are made 20 months or later after the subject has received a financial education unit. Taken together, Fernandes et al. (2014) confirm-on more solid empirical grounds- the conclusions drawn in earlier studies which survey the literature on financial education (Hastings et al. 2013; Hung et al. 2009), i.e. a lack of conclusive evidence as to whether a positive impact of financial education can be observed for consumers' financial behavior. Recently, Lührmann et al. (2015) extend the literature by an assessment of the effectiveness of a financial education program carried out among German high school students (My Finance Coach) and generally find a positive impact of that intervention on students' financial knowledge. With respect to financial behavior, the evidence depends on the different financial domains examined. While students participating in the program on average exhibit a higher propensity to suppress impulsive purchases, the authors do not find evidence of a significant increase with regard to savings.

\subsubsection{Reasons for ineffectiveness and potential remedies}

Fernandes et al. (2014) highlight that their findings should not be interpreted as evidence against the usefulness of financial education since a large number of 
financial education programs has never been evaluated and non-assessed initiatives obviously did not enter the sample. A number of reasons for the rather surprising finding of little effectiveness of educational interventions have been discussed in the literature. First, Fernandes et al. (2014) as well as Lusardi and Mitchell (2014), question the quality and motivation of teachers with respect to personal finance issues. As such, Way and Holden (2009), for example, find that less than $20 \%$ of high school teachers felt well prepared to teach personal finance topics. Moreover, individuals are heterogeneous in various dimensions. Lusardi and Mitchell (2013) show in a theoretical model that due to this heterogeneity, not everyone should change its behavior after receiving standardized financial training.

Moreover, while the average impact of financial education may be low, the literature has identified several circumstances in which an intervention might be promising. Lusardi and Mitchell (2014), in their review of related research, claim that financial education programs have to be targeted to specific groups in order to incorporate the heterogeneity of individuals. For example, the authors argue that females are ideal targets for specific financial literacy programs, since-other than the average male subject-they are aware of their low financial literacy levels. In their meta-analysis, Fernandes et al. (2014) have identified future directions for designing more successful programs. Specifically, they suggest that improving individuals' soft skills-e.g. their confidence to be proactive and their willingness to take investment risks - is likely more promising than teaching financial knowledge about, e.g., compound interest. In addition, since the authors find that the effect of financial education declines over time, promising programs should be designed as just-in-time interventions tied to a particular decision. In a recent study, GoeddeMenke et al. (2017) even suggest that one potential explanation for why financial literacy programs are mostly ineffective is the very fact that being financially literate is typically equated with having specific financial knowledge rather than having a basic understanding of fundamental economic concepts. In their study among German adolescents, the authors document that basic economic skills beneficially relate to both individual debt attitudes and behaviors while financial literacy levels turn out to be insignificant. Accordingly, they conclude that a stronger consideration of fundamental economic concepts in financial literacy programs might be a fruitful way to increase their effectiveness.

\subsection{Financial advice as a substitute for financial literacy?}

\subsubsection{Financial advice versus financial education}

While financial education programs have enjoyed strong political support as a means to address poor financial decision-making, Willis (2011) stresses that, besides the fact that they are unable to turn everyone into a financial expert, this should not be the path to take for reasons of efficient division of labor alone (see Sect. 6.1). Thus, instead of trying to educate inexperienced individuals, an alternative way to enhance the quality of their decisions on a market for financial services and products characterized by a growing complexity might be to delegate the job by relying on the services offered by professional financial 
advisors. ${ }^{37}$ Indeed, a large proportion of households seek expert advice when making financial decisions. Bluethgen et al. (2008) indicate that roughly $80 \%$ of individual investors in Germany turn to financial advisors for their investment decisions. In the U.S., $81 \%$ of the households investing in mutual funds, outside a retirement plan, rely on financial advice (ICI 2007), and 75\% of them seek advice before conducting stock market or mutual fund transactions (Hung and Yoong 2010).

However, the potential benefits of financial advice hinge on two important conditions. First, the advice itself must be accurate, suitable, and consistent with the client's goals. Whether financial expert intervention indeed benefits consumers remains controversial, though. While some studies concerned with household finance suggest that financial counseling can help individuals develop better financial practices and reduce their debt levels and delinquency rates (Collins and O'Rouke 2010; Agarwal et al. 2011), the evidence as to whether individuals' investment decisions benefit from expert financial advice is rather mixed. It could be shown that professionally-managed portfolios are better diversified (Bluethgen et al. 2008; Gerhardt and Hackethal 2009) and exhibit weaker disposition effects (Shapira and Venezia 2001) than portfolios of self-directed retail investors. Yet, a number of contributions in the field find that advised accounts are on average associated with higher costs, lower returns and inferior risk-return tradeoffs (Bergstresser et al. 2009; Hackethal et al. 2012; Kramer 2012) and conclude that advisors do not add value through their investment recommendations when judged relative to passive investment benchmarks (Foerster et al. 2014). Also, while there is some consensus that advice can improve retail investor portfolio decisions if conflicts of interest are mitigated (Bhattacharya et al. 2012; Hung and Yoong 2010), a typical advisor's incentive structure does in fact create a conflict of interest, leading advisors to reinforce biases of their clients instead of correcting them (Mullainathan et al. 2012) and tilt their recommendations towards costly transactions (Hoechle et al. 2015).

Notably, however, while the German government has done little to improve consumers' financial literacy by means of financial education initiatives, addressing the supply-side issues of retail financial markets has been the top priority of German regulatory authorities in recent years. With respect to financial advice, for instance, regulators now require banks to ask their clients for their prior investment experience before advising them on risky financial products. Moreover, financial advisors are required to assess the risk propensity of their clients before they are allowed to provide them with recommendations. Additionally, banks are obliged to provide advisees with product information sheets disclosing arguably decisionrelevant characteristics of financial products. Finally, regulators require advisors to

\footnotetext{
37 Yet another approach to support peoples' financial decision making process exploits a robust finding in behavioral economics, i.e. that different formulations of otherwise identical choice options (so-called frames) affect individuals' behavior. Accordingly, a mindful framing of peoples' decision environment (referred to as choice architecture) may be an additional avenue towards improved financial behavior. Indeed, this approach is promoted by, e.g., Choi et al. (2004) and Thaler and Benartzi (2004) who find that opt-out regimes in $401(\mathrm{k})$ pension plans result in a large and persistent increase in pension participation rates relative to conventional opt-in arrangements.
} 
prepare a detailed transcript of each client meeting which has to be authorized by the advisee. The rationale behind these regulations is that the reasons which prevent people from benefiting from financial advice are essentially rooted in the supply side and increasing access to neutral advice should solve the problem of poor financial decision-making. Similarly, regulatory authorities in the Netherlands and in the U.K. have recently enforced a new legislation prohibiting commissions for brokers and advisors altogether. Taken together, we state that regulators in Germany and elsewhere in the world have implemented a number of different measures banning incentives for biased financial advice. In what follows, we thus do not focus on potential conflicts of interest with respect to financial advice.

\subsubsection{Financial literacy and the demand for financial advice}

A second condition which must hold for professional financial advice to be able to substitute for financial literacy, is that low literate individuals must of course seek the support of professional advisors in the first place. Otherwise, measures imposed by regulators to protect consumers arguably will not benefit those who need them most. Thus, knowledge about how financial literacy relates to the demand for financial advice has recently received increasing attention among academics and policymakers.

The notion that financial advice can substitute for low levels of financial literacy rests on the assumption that less knowledgeable individuals face higher hurdles with regards to the collection and processing of information and thus save more on information and search costs when turning to an advisor. Moreover, low literate households may be less aware of potential conflicts of interest arising from advisors' typical incentive structures and hence more willing to assign an advisor with planning their personal finances (Inderst and Ottaviani 2009). Georgarakos and Inderst (2011) sketch an analytical framework of individual behavior in the context of financial advice using a "cheap-talk"-game in which uninformed investors must decide whether or not to trust the advice they receive whereas informed advisors can opt to ignore the advice. Thus, in their model, consumer information and financial advice are substitutes. Using a large-scale survey among households in $15 \mathrm{EU}$ countries, the authors empirically confirm that trust only matters for the less literate consumers. Similarly, Disney et al. (2015) recently analyze the decision of indebted consumers in the U.K. to ask for financial advice in the form of credit counseling and conclude that professional counseling substitutes for financial literacy: answering an additional financial literacy question correctly reduces the likelihood of an individual seeking assistance by roughly $60 \%$. As can be seen from Table 5, which provides a summary of the empirical evidence regarding the link between financial literacy and advice-seeking, other studies also provide evidence pointing to a negative relationship between financial literacy and the demand for expert financial advice. In the U.S., Hung and Yoong (2010) conduct an experiment among defined-contribution plan holders in the RAND American Life Panel and show that the least sophisticated were most likely to take advice, and Chalmers and Reuter (2012), applying a demographics-based financial literacy proxy, find that younger, less highly educated, and less well-paid (i.e. on average less financially 


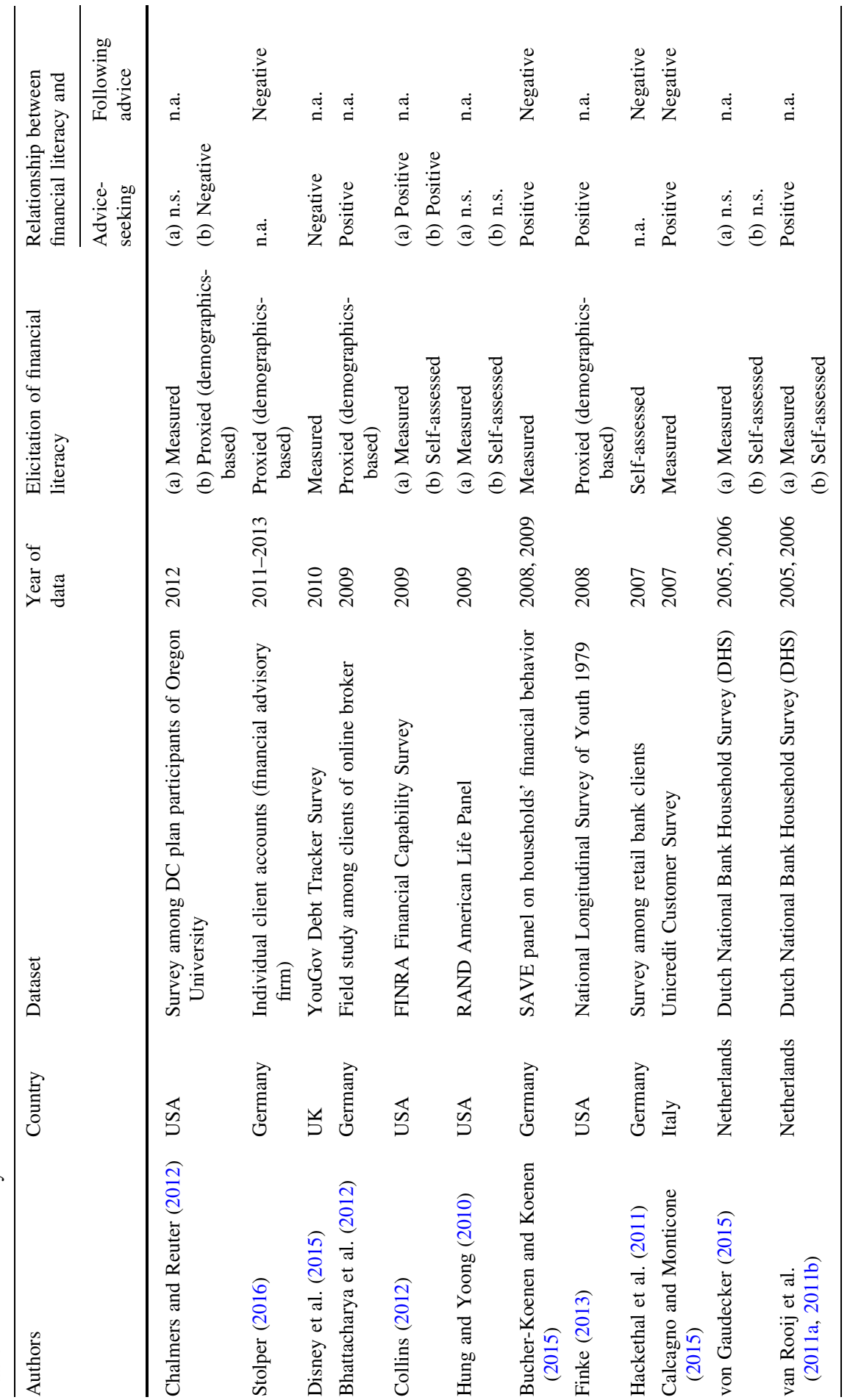




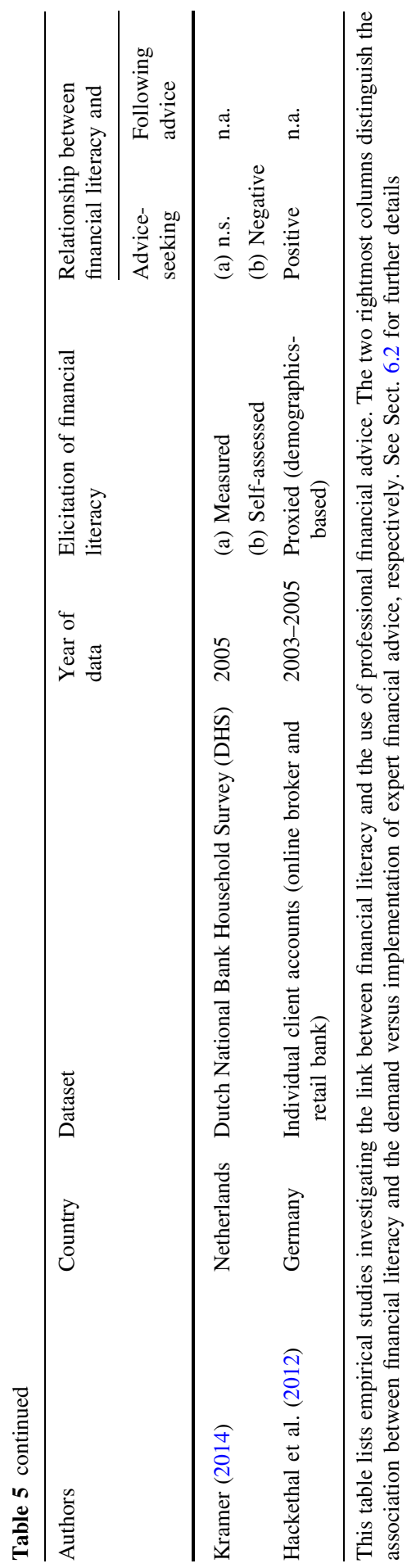


sophisticated) university employees are more likely to demand financial advice on defined-contribution retirement planning.

However, a growing number of studies in the field challenge the negative relationship between peoples' knowledge in financial matters and their propensity to seek expert assistance and instead point to a complementarity between financial literacy and financial advice. Bucher-Koenen and Koenen (2015) present a model in which advisors have an incentive to provide better advice to consumers who they perceive to be better informed, thus pointing to the fact that financial literacy and the quality of financial advice are complements rather than substitutes. In their analytical framework, it is assumed that advisees with better financial knowledge more likely understand the advice they obtain. This in turn provides the advisor with more incentives to develop sound recommendations for the financially sophisticated investors. Drawing on the 2008 and 2009 waves of the German SAVE household survey, the authors find that smarter investors indeed receive better advice, thus confirming their model predictions. In a related study, Bhattacharya et al. (2012) find that those customers of a German online broker who opted to obtain financial advice in a field study were among the most financially literate clients, and Hackethal et al. (2012) show that advisors of a large German retail bank are matched with wealthier and older investors (proxied to be more financially sophisticated), which also points to a complementarity of financial literacy and financial advice. The authors interpret their findings with respect to both the demand-side and the supply-side of advice. On the one hand, higher opportunity costs of time may induce wealthier clients to make use of financial advice, although they are relatively better prepared to perform the task themselves. On the other hand, financial advisors with commission-based compensation systems should have an incentive to prefer clients with substantial amounts of assets who are more likely to generate significant trading fees.

Empirical evidence indicating that professional financial advice serves as a complement rather than a substitute for financial literacy is not limited to the German market, though. In the US, Collins (2012) uses data from the 2009 FINRA Financial Capability Survey and finds that individuals with higher incomes, higher educational attainment, and higher levels of financial literacy are most likely to receive financial advice. Similarly, Finke (2013) draws on the 2008 wave of the National Longitudinal Survey and documents that financial sophistication increases the demand for financial advice: those individuals most likely to seek advice are not those who are most prone to make financial mistakes. Corroborating this empirical evidence, van Rooij et al. (2011b) exploit the Dutch Household Survey (DHS) and show that people who are less financially literate rely more on informal sources of financial advice, such as friends and family.

Finally, the finding that low literate individuals rely less on expert advice also ties in with psychological evidence, which challenges the notion that people are sophisticated enough to turn to advice in order to overcome their own lack of financial capability. By contrast, this literature suggests that individuals who do not know much about a subject tend not to recognize their ignorance and therefore typically fail to seek better information (Kruger and Dunning 1999). 


\subsubsection{Test-based versus self-assessed financial literacy and the role of overconfidence in seeking financial advice}

In a recent contribution, Kramer (2014) suggests that the ambiguous results as to the role of financial knowledge for advice-seeking may at least partly be explained by the different approaches that have been employed to elicit financial literacy. He concludes that studies using self-assessed financial literacy typically find a negative relationship with demanding advice, while those that rely on test-based financial literacy report a positive or insignificant relationship. This discrepancy between the role of self-assessed versus test-based financial literacy implies a role for overconfidence as proposed in the model of Guiso and Jappelli (2006) in which overconfident investors are less willing to rely on information provided by financial advisors, banks or brokers and more likely to collect information directly because they perceive their self-collected information to be of better quality than it actually is. Using the DHS survey data, Kramer (2014) explicitly differentiates between selfreported and objectively elicited financial literacy and shows that confidence in one's own knowledge is negatively related to asking for help, while actual expertise is not significantly associated with seeking professional financial advice. This finding is confirmed in another recent study based on the DHS data, which analyzes the role of financial literacy and financial advice for households' portfolio diversification and does not find a significant association between financial literacy and the likelihood of turning to financial advice (von Gaudecker 2015). However, most losses from insufficient diversification are spotted among overconfident investors, which neither are financially literate nor consult with financial advisors.

\subsubsection{How does financial literacy relate to the propensity to follow advice?}

While seeking financial advice is an important step for the low literate in order to arrive at more informed decisions, one would also like to know if they choose to follow the advice they receive in order to properly assess the potential of professional advice as a substitute for financial literacy. Clearly, financial advice does not translate into sound financial decisions if individuals do not act on the recommendations of their advisors. Surprisingly, however, the question of whether advisees in fact implement the advice they receive is still largely unanswered and very few contributions have considered the role of financial literacy when it comes to following expert advice. The rightmost column of Table 5 summarizes the empirical evidence pertaining to this link.

Calcagno and Monticone (2015) present a stylized model of strategic interaction between advisees and better informed advisors with conflicts of interest. Unlike previous research, however, the authors allow for different degrees of interaction intensity ranging from consulting the advisor in order to enhance one's information set to completely delegating all decisions to her. Consistent with the framework of Bucher-Koenen and Koenen (2015), the model predicts that the more financially sophisticated are more likely to consult with financial advisors because they anticipate that they will receive valuable information from their advisors. However, once low literate individuals decide to seek the help of financial experts, they are 
more likely to delegate the decision-making entirely to the advisor. Using data from a survey among the retail customers of Italy's largest bank, the authors empirically confirm the model predictions showing that financial literacy indeed appears to play a role when it comes to how people implement the advice which they receive from their advisors.

Several studies drawing on German data corroborate the negative relationship between financial literacy and the propensity to follow financial advice. Hackethal et al. (2011), who study the trading behavior of advised retail clients using data from German brokerage accounts, find that they are less likely to implement the advice given to them when their financial sophistication is higher. Bucher-Koenen and Koenen (2015) also document a negative relationship between financial knowledge and advisees' self-reported propensity to follow advisors' recommendations. Finally, Stolper (2016) directly matches the recommendations of financial advisors at a German advisory firm with their clients' post-advice account activity and find that the degree of following the advice is highest for those exhibiting the lowest levels of financial literacy.

\subsubsection{Discussion}

To rationalize the ambiguous impact of financial literacy on the use of financial advice, it is argued in the literature that financial sophistication carries two dimensions, i.e. the ability to understand advice on the one hand, and the literacy to question it as well as to process information privately (a possibility which Bucher-Koenen and Koenen 2015, refer to as outside option), on the other hand. While the skills to understand the advice increase the propensity of demanding it, the competence to challenge the advice, along with the ability to collect and handle private information, reduces the likelihood of following it. This is because the financially sophisticated advisee understands the advice and only opts to follow it if she prefers the recommendations to searching on her own, while she ignores it otherwise.

To conclude, the evidence on whether financial advice can be considered a substitute for financial literacy is inconsistent. While some studies document the required negative relationship between the two potential channels to improve financial decision-making, several studies challenge this view by showing that those who would benefit the most from advice are least likely to seek it. Once the advice has been obtained, however, recent contributions to the literature suggest that it is indeed the low literate who are most likely to follow it.

\section{Conclusion}

\subsection{Summary}

We review the literature on the rapidly evolving field of financial literacy. Interestingly, although the topic has become an important field in academia and also attracts the attention of policymakers around the globe, a universally accepted definition of the term has not yet been offered. Consequently, it comes to no surprise 
that there is no common operationalization, either. Instead, various measures for financial literacy have been developed, mostly based on a set of questions included in household surveys. Initially proposed as a starting point to measure financial literacy, Lusardi and Mitchell (2008) have developed a parsimonious set of three questions related to financial literacy which have now become known as the Big Three. By now, these questions have become the gold standard in measuring individuals' financial knowledge and abilities and have been incorporated in many household surveys around the world, including the novel PHF survey for Germany.

Focusing on the empirical evidence regarding the Big Three questions, we document that the level of financial literacy is generally rather low and we also find substantial differences between national economies and demographic cohorts. In particular, financial literacy turns out to be considerably lower in transition economies and lower-income economies as compared to industrial economies, a finding which is also corroborated in the recently conducted Standard and Poors FinLit Survey (Klapper et al. 2015). According to Klapper et al. (2015) as well as our analyses of the data provided by the PHF survey, financial literacy levels of German citizens are among the highest in the world. However, even in Germany almost half of the survey participants are not able to answer all Big Three questions correctly, leaving room for substantial improvements of financial literacy. In addition, in Germany and elsewhere, the elderly and the young as well as the least educated and lowest-income individuals possess particularly low literacy levels. These groups have the highest propensity to commit financial mistakes. Thus, policy makers and interest groups around the world have put considerable effort in increasing peoples' financial literacy. As becomes obvious from our review of the literature, however, the educational initiatives yielded rather disappointing results and apparently, their capability to improve the quality of financial behavior is limited. Thus, improving the effectiveness of the programs seems key in order to literate individuals to sufficient levels. We also review the current literature on financial advice, since financial advice might act as a substitute for financial literacy, thereby improving individuals' financial decision making without treating them to extensive financial education programs. By and large, the corresponding evidence is inconclusive but promising if moral hazard issues leading to conflicts of interests in the advisor-advisee relationship can be effectively mitigated or even eliminated.

\subsection{Directions for future research}

In what follows, we would like to highlight a number of topics which-from our perspective-represent fruitful avenues for future research. First, the majority of research on financial literacy has been conducted with a geographic focus on the U.S. and there is far less evidence available for Europe, e.g. for Germany. Does this focus on the U.S. pose an issue to our knowledge about individuals' financial literacy? We believe the answer is yes: financial decisions faced by U.S. citizens and German citizens, for instance, differ a great deal.

Specifically, one of the major financial issues pertaining to the asset side of a U.S. household's balance sheet is the investment decision concerning 401(k) plans as 
part of a company pension scheme. How much should one contribute to the plan in order to maximize matching of the employer and how should the contributions be invested wisely across asset classes and financial products? In Germany, unlike in the U.S., decisions regarding defined contribution plans are much less relevant. On the one hand, the public pension system is still comparably generous and payments from corporate pension plans for retirees are of subordinate importance. On the other hand, plan participants in Germany usually do not have the discretion to determine the asset allocation of contributions. Thus, financial literacy is not as relevant when it comes to this decision. Although the designs of company pension schemes differ substantially between the two countries, a German household's choice whether or not to participate in state-subsidized private pensions schemes (most prominently Riester plans) is comparable to decisions faced when dealing with 401(k) plans along several dimensions. Consequently, we encourage more research in the vein of Coppola and Gasche (2011) in the future.

From a German perspective, we currently see one additional major issue with respect to financial literacy and financial decision making that is rarely addressed in the literature, most probably because it is rather specific to Germans savers: due to a lack of knowledge and experience regarding stockholdings and equity mutual fund investments, an overwhelming majority of German households is still exclusively invested in savings products. Clearly, this investment strategy is quasi deterministically associated with a loss in household purchasing power in times of interest levels persistently close to zero. We believe that extending the conceptualization and measurement of financial literacy including knowledge about the long-run distributional characteristics of stock investment returns can be a promising avenue to increase the below-average willingness to participate in the stock market observed among Germans.

Turning the attention to the liability side of the household's balance sheet, U.S. Americans and Germans also face very different challenges. While households in the U.S. were exposed to highly complex mortgage arrangements prior to the subprime crisis, plain vanilla debt contracts have been dominant in Germany ever since. In addition, issues like illiterate credit card use have typically been much less of an issue in Germany since credit card balances are charged against the cardholder's bank account on a monthly basis. Thus, financial debt literacy appears less of an issue in Germany than in the U.S.

Recently, there has been notable progress in fostering research outside the U.S. The PHF survey, for instance, gives researchers the opportunity to relate financial literacy to various demographics as well as to a number of financial decisions of households. With the second wave of the PHF survey available for scientific use since April 2016, scholars are now able to conduct detailed analyses of households' financial situation across subjects and over time. We are looking forward to interesting and novel insights concerning the relationship between financial literacy and financial behavior in the German context based on this rich dataset. For future cross-country analyses, it is crucial that survey data is elicited using a consistent methodological approach (e.g. identical selection and training criteria for interviewers) in all participating countries to ensure comparability of outcomes. The launch of the Eurosystem Household Finance and Consumption Survey 
(HFCS) - the German part of it covered via the PHF-marks a first step in this direction. Similarly, we embrace other cross-country initiatives such as the abovementioned OECD initiative and S\&P's Finlit Survey both of which elicit consistent and readily comparable data across a number of different countries.

Although we observe a positive development with regard to cross-country household surveys, we have to acknowledge that research based on household surveys is anything but unproblematic. As Meyer et al. (2015) have shown, household surveys are subject to issues regarding the quality of data elicited. Related challenges affect both the measurement of financial literacy itself and the financial behavior captured in surveys on households' financial situation. We believe that linking individuals' financial literacy directly with their real-world financial decisions, as is done in Choi et al. (2011), Clark et al. (2015) and Stolper (2016), for instance, is a promising approach in order to enhance the quality of empirical results obtained in financial literacy research.

Finally, the research we review in this paper relates to the relevance of financial literacy in the context of household finance. Although financial mistakes associated with low financial literacy correlate with high costs for households, low levels of financial literacy might also be important in a business context. ${ }^{38}$ Decision makers in blue-collar business, for instance, often are not especially knowledgeable in financial matters. Yet, they frequently make a range of finance-related decisions such as paying invoices in due time and aggregating costs for estimates they give. Of course, one could argue that individuals are less prone to financial mistakes if they act as professionals. However, the literature on behavioral biases has documented less severe but still significant investment mistakes conducted by, for instance, money managers (e.g., Kaustia et al. 2008). In this spirit, the research of Bodnaruk and Simonov (2015) is an interesting example for simultaneously analyzing individuals' financial behavior in the private and in the professional domain. To us, it appears that financial literacy in the business context is an interesting and still largely under-researched subject: as can be inferred from Table 1, 19 out of the 20 most cited papers focus on financial decisions of households, the only exception being McDaniel et al. (2002), who discuss financial literacy in the context of audit committees.

\subsection{Policy recommendations}

As far as policy recommendations are concerned, we propose a holistic approach. Based on the empirical evidence on individuals' financial literacy level that we review in this paper, it seems important to pursue a policy mix that does not treat financial literacy and financial education separately but instead incorporates their interdependence with potential substitutes like financial advice, the implementation of an intelligent choice architecture and a thoughtful regulation concerning financial products offered to households. Indeed, this multi-dimensional approach is currently

\footnotetext{
38 Please note that the Kreditanstalt für Wiederaufbau (KfW) as of the 2014 wave inserted financial literacy questions into the Gründungsmonitor survey of entrepreneurs in Germany. In particular, the respondents have to self-assess their financial literacy as well as to answer the Big Three and three other questions on financial literacy.
} 
the way of choice in many countries. Moreover, even though evidence regarding the effectiveness of financial education programs with respect to financial decision making is at best mixed, we want to highlight the relevance of enabling citizens when it comes to financial matters. Prior to the financial crisis, many private (and professional) market participants bought products whose underlying mechanisms they did not understand, e.g. overly complex certificates or mortgage backed securities (MBS). Collectively, these financial products were dismissed as toxic or-quoting investment legend Warren Buffet-as "weapons of mass destruction". However, financial innovations have served their goal to improve and facilitate financial products and services for the most part. In fact, functioning financial markets require peoples' acceptance of financial innovations and sufficient knowledge and ability regarding financial matters is an indispensable foundation for this acceptance.

Acknowledgements We gratefully acknowledge the comments of Christina Bannier and Wolfgang Breuer, the editors, as well as two anonymous referees. Moreover, we would like to thank Dennis Bär, Daniel Czaja, Lea Meyer and Tobias Meyll for excellent research assistance.

Open Access This article is distributed under the terms of the Creative Commons Attribution 4.0 International License (http://creativecommons.org/licenses/by/4.0/), which permits unrestricted use, distribution, and reproduction in any medium, provided you give appropriate credit to the original author(s) and the source, provide a link to the Creative Commons license, and indicate if changes were made.

\section{Appendix: Panel on Household Finances (PHF): data description}

We draw on novel survey data on household finance and wealth provided by the Deutsche Bundesbank in the Panel on Household Finances (PHF) which is representative of the German population. In the first wave of the PHF, face-to-face computer aided interviews were conducted between September 2010 and July 2011 with the financially knowledgeable persons (one per household) in a sample of 3565 households in total. Questions cover a wide range of items related to the household balance sheet including financial and non-financial assets as well as household debt. This information is then supplemented with demographic and psychological characteristics of the household members as well as a household-specific financial literacy score. The PHF features (a) survey weights to adjust for the oversampling of wealthy households during the data collection and (b) multiple imputations in order to mitigate the issue of missing data due to item non-response. We make use of the survey weights and the corresponding replicate weights to adjust point estimates as well as variance and standard error estimates in all our baseline analyses. Note that this correction of the sampling design does not materially affect our results (corresponding tables available upon request). Similarly, for the independent variables, we use the average of the five imputed values provided in the data. For robustness, we re-estimate our main model using multiple imputations via Rubin's rule (Rubin 1996). Results remain virtually unchanged and are also available upon request. 


\section{References}

Agarwal S, Driscoll J, Gabaix X, Laibson D (2011) Learning in the credit card market. Working paper Agnew S, Harrison N (2015) Financial literacy and student attitudes to debt: a cross national study examining the influence of gender on personal finance concepts. J Retail Consum Serv 25:122-129. doi:10.1016/j.jretconser.2015.04.006

Agnew JR, Szykman LR (2005) Asset allocation and information overload: the influence of information display, asset choice, and investor experience. J Behav Financ 6(2):57-70. doi:10.1207/ s15427579jpfm0602_2

Agnew JR, Bateman H, Thorp S (2013) Financial literacy and retirement planning in Australia. Numeracy 6(2):1-25. doi:10.5038/1936-4660.6.2.7

Alessie, R, Van Rooij M, Lusardi A (2011) Financial literacy and retirement preparation in the Netherlands. J Pension Econo Financ (10):527-545. doi:10.1017/S1474747211000461

Allgood S, Walstad W (2013) Financial literacy and credit card behaviors: a cross-sectional analysis by age. Numeracy. doi:10.5038/1936-4660.6.2.3

Allgood S, Walstad WB (2016) The effects of perceived and actual financial literacy on financial behaviors. Econ Inq 54(1):675-697. doi:10.1111/ecin.12255

Almenberg J, Säve-Söderbergh J (2011) Financial literacy and retirement planning in Sweden. J Pension Econ Financ (10):585-598. doi:10.1017/S1474747211000497

Alsemgeest L (2015) Arguments for and against financial literacy education: Where to go from here? Int J Consum Stud 39:155-161. doi:10.1111/ijcs.12163

Angrist J, Krueger A (2001) Instrumental variables and the search for identification: from supply and demand to natural experiments. J Econ Perspect 15(4):69-85. doi:10.1257/jep.15.4.69

Arrondel L, Debbich M, Savignac F (2013) Financial literacy and financial planning in France. Numeracy 6(2). doi:10.5038/1936-4660.6.2.8

Asaad CT (2015) Financial literacy and financial behavior: assessing knowledge and confidence. Financ Serv Rev 24(2):101-117

Balloch A, Nicolae A, Philip D (2015) Stock market literacy, trust, and participation. Rev Financ 19(5):1925-1963. doi:10.1093/rof/rfu040

Banks J, Oldfield Z (2007) Understanding pensions: cognitive function, numerical ability and retirement saving. Fiscal Stud 28(2):143-170. doi:10.1111/j.1475-5890.2007.00052.x

Banks J, Crawford R, Tetlow G (2015) Annuity choices and income drawdown: evidence from the decumulation phase of defined contribution pensions in England. $J$ Pension Econ Financ 14(04):412-438. doi:10.1017/S1474747215000256

Bannier CE, Neubert M (2016a) Actual and perceived financial sophistication and wealth accumulation: the role of education and gender. Working paper

Bannier CE, Neubert M (2016b) Gender differences in financial risk taking: the role of financial literacy and risk tolerance. Econ Lett 145:130-135

Bayer PJ, Bernheim BD, Scholz JK (2009) The effects of financial education in the workplace: Evidence from a survey of employers. Econ Inq 47(4):605-624. doi:10.1111/j.1465-7295.2008.00156.x

Beckmann E (2013) Financial literacy and household savings in Romania. Numeracy 6(2):1-22. doi:10. 5038/1936-4660.6.2.9

Behrman JR, Mitchell OS, Soo CK, Bravo D (2012) How financial literacy affects household wealth accumulation. Am Econ Rev 102(3):300-304. doi:10.1257/aer.102.3.300

Bell C, Gorin D, Hogarth JM (2009) Does financial education affect soldiers' financial behavior? Networks Financial Institute Working paper no. 8

Bergstresser D, Chalmers JMR, Tufano P (2009) Assessing the costs and benefits of brokers in the mutual fund industry. Rev Financ Stud 22(10):4129-4156. doi:10.1093/rfs/hhp022

Bernheim BD, Garrett DM, Maki DM (2001) Education and saving: the long-term effects of high school financial curriculum mandates. J Publ Econ 80(3):435-465. doi:10.1016/S0047-2727(00)00120-1

Bhattacharya U, Hackethal A, Kaesler S, Loos B, Meyer S (2012) Is unbiased financial advice to retail investors sufficient? Answers from a large field study. Rev Financ Stud 25(4):975-1032. doi:10. 1093/rfs/hhr127

Bilias Y, Georgarakos D, Haliassos M (2010) Portfolio inertia and stock market fluctuations. J Money Credit Bank 42(4):715-742. doi:10.1111/j.1538-4616.2010.00304.x

Bluethgen R, Meyer S, Hackethal A (2008) High-quality advice wanted. Working paper 
Bodnaruk A, Simonov A (2015) Do financial experts make better investment decisions? J Financ Intermed 24(4):514-536. doi:10.1016/j.jfi.2014.09.001

Brown M, Graf R (2013) Financial literacy and retirement planning in Switzerland. Numeracy. doi:10. 5038/1936-4660.6.2.6

Bruine de Bruin W, Vanderkklaauw W, Downs JS, Fischhoff B, Topa G, Armantier O (2010) Expectations of inflation: The role of demographic variables, expectation formation, and financial literacy. J Consum Aff 44:381-402. doi:10.1111/j.1745-6606.2010.01174.x

Browning M, Leth-Petersen S (2003) Imputing consumption from income and wealth information. Econ J 113(488):282-301. doi:10.1111/1468-0297.00135

Bucciol A, Veronesi M (2014) Teaching children to save and lifetime savings: What is the best strategy? J Econ Psychol 27:1-17

Bucher-Koenen T (2011) Financial literacy, Riester pensions, and other private old age provision in Germany. MEA Discussion Paper

Bucher-Koenen T, Koenen J (2015) Do seemingly smarter consumers get better advice? MEA Discussion Paper

Bucher-Koenen T, Lusardi A (2011) Financial literacy and retirement planning in Germany. J Pension Econ Financ 10(4):565-584. doi:10.1017/S1474747215000311

Bucher-Koenen T, Ziegelmeyer M (2014) Once burned, twice shy? Financial literacy and wealth losses during the financial crisis. Rev Financ 18(6):2215-2246. doi:10.1093/rof/rft052

Bucher-Koenen T, Lusardi A, Alessie RJM, van Rooij MCJ (2016) How financially literare are women? An overview and new insights. J Consum Aff. doi:10.1111/joca.12121

Calcagno R, Monticone C (2015) Financial literacy and the demand for financial advice. J Bank Financ 50:363-380. doi:10.1016/j.jbankfin.2014.03.013

Calvet LE, Campbell JY, Sodini P (2007) Down or out: assessing the welfare costs of household investment mistakes. J Polit Econ 115(5):707-747

Calvet LE, Campbell JY, Sodini P (2009) Measuring the financial sophistication of households. Am Econ Rev 99(2):393-398

Carlin BI, Robinson DT (2012) What does financial literacy training teach us? J Econ Educ 43(3):235-247. doi:10.1080/00220485.2012.686385

Carpena F, Cole SA, Shapiro J, Zia B (2011) Unpacking the causal chain of financial literacy. World Bank Policy Research Working Paper No. 5798

Chalmers J, Reuter J (2012) How do retirees value life annuities? Evidence from public employees. Rev Financ Stud 25(8):2601-2634

Chan S, Stevens AH (2008) What you don't know can't help you: pension knowledge and retirement decision-making. Rev Econ Stat 90(2):253-266

Choi JJ, Laibson D, Madrian BC (2004) Plan design and 401(k) savings outcomes. Natl Tax J 57(2):275-298

Choi JJ, Laibson D, Madrian BC, Metrick A (2009) Reinforcement learning and savings behavior. J Financ 64(6):2515-2534. doi:10.1111/j.1540-6261.2009.01509.x

Choi JJ, Laibson D, Madrian BC (2011) \$100 bills on the sidewalk: suboptimal investment in 401(k) plans. Rev Econ Stat 93(3):748-763

Christelis D, Jappelli T, Padula M (2010) Cognitive abilities and portfolio choice. Eur Econ Rev 54(1):18-38. doi:10.1016/j.euroecorev.2009.04.001

Christiansen C, Joensen JS, Rangvid J (2008) Are economists more likely to hold stocks? Rev Financ 12(3):465-496. doi:10.1093/rof/rfm026

Clark R, Lusardi A, Mitchell OS (2015) Financial knowledge and 401(k) investment performance: a case study. J Pension Econ Financ. doi:10.1017/S1474747215000384

Cole S, Sampson T, Zia B (2011) Prices or knowledge? What drives demand for financial services in emerging markets? J Financ (66):1933-1967. doi:10.1111/j.1540-6261.2011.01696.x

Collins JM (2012) Financial advice: A substitute for financial literacy? Financ Serv Rev 21(4):307-322

Collins JM, O'Rourke CM (2010) Financial education and counseling-still holding promise. J Consum Aff 44(3):483-498. doi:10.1111/j.1745-6606.2010.01179.x

Collins JM, Gorey RN, Schmeiser MD, Baker CA, Ziegler D (2009) Building indicators measures: analysis and recommendations. Anne E. Casey Foundation, Baltimore

Coppola M, Gasche M (2011) Die Riester-Förderung-Das unbekannte Wesen (Riester Subsidy-The Unknown Entity). MEA Discussion Paper

Crossan D, Feslier D, Hurnard R (2011) Financial literacy and retirement planning in New Zealand. J Pension Econ Financ (10):619-635. doi:10.1017/S1474747211000515 
Danes SM, Huddleston-Casas C, Boyce L (1999) Financial planning curriculum for teens: Impact evaluation. J Financ Couns Plan 10(1):26-39

de Bassa SC (2013) Financial literacy and financial behavior among young adults: evidence and implications. Numeracy 6(2):1-21. doi:10.5038/1936-4660.6.2.5

Deevy M, Lucich S, Beals M (2012) Scams, schemes and swindles-a review of consumer financial fraud research. Working paper

Delavande A, Rohwedder S, Willis R (2008) Preparation for retirement, financial literacy and cognitive resources. Retrieved from http://ssrn.com/abstarct=1337655

Deuflhard F, Georgarakos D, Inderst R (2014) Financial literacy and savings account returns. Retrieved from http://papers.ssrn.com/abstract=2358564

Dhar R, Zhu N (2006) Up close and personal: investor sophistication and the disposition effect. Manag Sci 52(5):726-740. doi:10.1287/mnsc.1040.0473

Disney R, Gathergood J (2013) Financial literacy and consumer credit portfolios. J Bank Financ 37(7):2246-2254. doi:10.1016/j.jbankfin.2013.01.013

Disney R, Gathergood J, Weber J (2015) Credit counseling: A substitute for consumer financial literacy? J Pension Econ Financ 14(04):466-491. doi:10.1017/S1474747215000219

Feng L, Seasholes MS (2005) Do investor sophistication and trading experience eliminate behavioral biases in financial markets? Rev Financ 9(3):305-351. doi:10.1007/s10679-005-2262-0

Fernandes D, Lynch JG Jr, Netemeyer RG (2014) Financial literacy, financial education, and downstream financial behaviors. Manag Sci 60(8):1861-1883. doi:10.1287/mnsc.2013.1849

Finke MS (2013) Financial advice: Does it make a difference? In: Mitchell, Smetters (eds) The market for retirement financial advice. Oxford University Press, Oxford

Finke MS, Howe JS, Huston SJ (2016) Old age and the decline in financial literacy. Manag Sci. doi:10. 1287/mnsc.2015.2293

Foerster S, Linnainmaa J, Melzer B, Previtero A (2014) The costs and benefits of financial advice Working paper

Fonseca R, Mullen KJ, Zamarro G, Zissimopoulos J (2012) What explains the gender gap in financial literacy? The role of household decision making. J Consum Aff 46(1):90-106. doi:10.1111/j.17456606.2011.01221.x

Forneo E, Monticone C (2011) Financial literacy and pension plan participation in Italy. J Pension Econ Financ (10):547-564 doi:10.1017/S1474747211000473

Gamble KJ, Boyle PA, Yu L, Bennett DA (2015) Aging and financial decision making. Manag Sci 61(11):2603-2610. doi:10.1287/mnsc.2014.2010

Gathergood J (2012) Self-control, financial literacy and consumer over-indebtedness. J Econ Psychol 33(3):590-602

Genesove D, Mayer C (2001) Loss aversion and seller behavior: evidence from the housing market. Q J Econ 116(4):1233-1260. doi:10.1162/003355301753265561

Georgarakos D, Inderst R (2011) Financial advice and stock market participation. ECB Working paper

Georgarakos D, Pasini G (2011) Trust, sociability, and stock market participation. Rev Financ 15:693-725

Gerardi K, Goette L, Meier S (2013) Numerical ability predicts mortgage default. Proc Natl Acad Sci USA 110(28):11267-11271. doi:10.1073/pnas.1220568110

Gerhardt R, Hackethal A (2009) The influence of financial advisors on household portfolios: a study on private investors switching to financial advice. Working paper

Goedde-Menke M, Erner C, Oberste M (2017) Towards more sustainable debt attitudes and behaviors: the importance of basic economic skills. J Bus Econom (Forthcoming)

Goetzmann WN, Kumar A (2008) Equity portfolio diversification. Rev Financ 12(3):433-463. doi:10. 1093/rof/rfn005

Graham JR, Harvey CR, Huang H (2009) Investor competence, trading frequency, and home bias. Manag Sci 55(7):1094-1106

Grinblatt M, Keloharju M (2001) How distance, language, and culture influence stockholdings and trades. J Financ 56(3):1053-1073

Grinblatt M, Keloharju M, Linnainmaa J (2009) Do smart investors outperform dumb investors? CRSP Working paper no. 09-33

Grinblatt M, Keloharju M, Linnainmaa JT (2011) IQ and stock market participation. J Financ 66(6):2121-2164. doi:10.1111/j.1540-6261.2011.01701.x

Grinblatt M, Keloharju M, Linnainmaa JT (2012) IQ, trading behavior, and performance. J Financ Econ 104(2):339-362. doi:10.1016/j.jfineco.2011.05.016 
Grohmann A, Kouwenberg R, Menkhoff L (2015) Childhood roots of financial literacy. J Econ Psychol 51:114-133. doi:10.1016/j.joep.2015.09.002

Guiso L, Jappelli T (2006) Information acquisition and portfolio performance, CEPR Working paper \#5901

Guiso L, Jappelli T (2008) Financial literacy and portfolio choice. EUI Working papers no. ECO2008/31

Guiso L, Viviano E (2015) How much can financial literacy help? Rev Financ 19(4):1347-1382. doi:10. 1093/rof/rfu033

Hackethal A, Inderst R, Meyer S (2011) Trading on advice. Working paper

Hackethal A, Haliassos M, Jappelli T (2012) Financial advisors: A case of babysitters? J Bank Financ 36(2):509-524. doi:10.1016/j.jbankfin.2011.08.008

Hastings JS, Mitchell OS (2011) How financial literacy and impatience shape retirement wealth. NBER Working paper no. 16740

Hastings JS, Madrian BC, Skimmyhorn WL (2013) Financial literacy, financial education, and economic outcomes. Annu Rev Econ 5:347-373. doi:10.1146/annurev-economics-082312-125807

Heinberg A, Hung AA, Kapteyn A, Lusardi A, Yoong JK (2010) Five steps to planning success. RAND Working paper no. WR-790-SSA

Hilgert MA, Hogarth JM, Beverly SG (2003) Household financial management: the connection between knowdlege and behavior. Federal Reserv Bull 89(7):309-322

Hoechle D, Ruenzi S, Schaub N, Schmid M (2015) Financial advice and bank profits. Working paper

Hoffmann AOI, Post T, Pennings JME (2013) Individual investor perceptions and behavior during the financial crisis. J Bank Financ 37(1):60-74. doi:10.1016/j.jbankfin.2012.08.007

Howlett E, Kees J, Kemp E (2008) The role of self-regulation, future orientation, and financial knowledge in long-term financial decisions. J Consum Aff 42:223-242. doi:10.1111/j.1745-6606.2008.00106.X

Hsu JW (2011) Aging and strategic learning: the impact of spousal incentives on financial literacy (Networks Financial Institute No. 6)

Hung AA, Yoong JK (2010) Asking for help survey and experimental evidence change. RAND Working paper no. WR-714-1

Hung AA, Parker AM, Yoong JK (2009) Defining and measuring financial literacy. RAND Working paper series no. 708

Huston SJ (2010) Measuring financial literacy. J Consum Aff 44(2):296-316. doi:10.1111/j.1745-6606. 2010.01170.x

Inderst R, Ottaviani M (2009) Misselling through agents. Am Econ Rev 99(3):883-908. doi:10.1257/aer. 99.3.883

Investment Company Institute (2007) Why do mutual fund investors use professional financial advisors? Res Fundam 16(1):1-8

Jappelli T (2010) Economic literacy: an international comparison. Econ J 120:F429-F451. doi:10.1111/j. 1468-0297.2010.02397.x

Jappelli T, Padula M (2013) Investment in financial literacy and saving decisions. J Bank Financ 37(8):2779-2792. doi:10.1016/j.jbankfin.2013.03.019

Jappelli T, Padula M (2015) Investment in financial literacy, social security, and portfolio choice. J Pension Econ Financ 14(4):369-411. doi:10.1017/S1474747214000377

Kaustia M, Alho E, Puttonen V (2008) How much does expertise reduce behavioral biases? The case of anchoring effects in stock return estimates. Financ Manag 37(3):391-411

Kimball MS, Shumway T (2006) Investor sophistication and the home bias, diversification, and employer stock puzzles. Working paper

Klapper L, Panos GA (2011) Financial literacy and retirement planning: the Russian case. J Pension Econ Financ 10(4):599-618. doi:10.1017/S1474747211000503

Klapper L, Lusardi A, Panos GA (2013) Financial literacy and its consequences: evidence from Russia during the financial crisis. J Bank Financ 37(10):3904-3923

Klapper L, Lusardi A, van Oudheusden P (2015) Financial literacy around the word: insights from the Standard \& Poor's rating services global financial literacy survey. http://gflec.org/wp-content/ uploads/2015/11/Finlit_paper_16_F2_singles.pdf

Koestner M, Meyer S, Hackethal A (2017) Do individual investors learn from their experience? J Bus Econom (Forthcoming)

Korniotis GM, Kumar A (2013) Do portfolio distortions reflect superior information or psychological biases? J Financ Quant Anal 48(01):1-45. doi:10.1017/S0022109012000610

Kozup J, Hogarth JM (2008) Financial literacy, public policy, and consumers' self-protection-More questions, fewer answers. J Consum Aff 42:127-136. doi:10.1111/j.1745-6606.2008.00101.x 
Kramer MM (2012) Financial advice and individual investor portfolio performance. Financ Manag 41(2):395-428. doi:10.1111/j.1755-053X.2012.01185.x

Kramer MM (2014) Financial literacy, overconfidence and financial advice seeking. Working paper

Kruger J, Dunning D (1999) Unskilled and unaware of it: how difficulties in recognizing one's own imcompetence lead to. J Pers Soc Psychol 77(6):1121-1134

Lachance M-E (2014) Financial literacy and neighborhood effects. J Consum Aff 48(2):251-273. doi:10. 1111/joca.12024

Lührmann M, Serra-Garcia M, Winter J (2015) Teaching teenagers in finance: Does it work? J Bank Financ 54:160-174. doi:10.1016/j.jbankfin.2014.11.009

Lusardi A (2012) Numeracy, financial literacy, and financial decision-making. NBER Working paper no. 17821

Lusardi A (2015) Financial literacy skills for the 21st century: evidence from PISA. J Consum Aff 49(3):639-659. doi:10.1111/joca.12099

Lusardi A, de Bassa Scheresberg C (2013) Financial literacy and high-cost borrowing in the United States (NBER Working paper series no. 18969). Retrieved from http://www.nber.org/papers/w18969

Lusardi A, Mitchell OS (2007) Baby boomer retirement security: the roles of planning, financial literacy, and housing wealth. J Monet Econ 54(1):205-224. doi:10.1016/j.jmoneco.2006.12.001

Lusardi A, Mitchell OS (2008) Planning and financial literacy: How do women fare? Am Econ Rev 98(2):413-417. doi:10.3386/w13750

Lusardi A, Mitchell OS (2009) How ordinary consumers make complex economic decisions: financial literacy and retirement readiness. NBER Working paper no. 15350

Lusardi A, Mitchell OS (2011a) Financial literacy and planning: implications for retirement well-being. In: Mitchell OS, Lusardi A (eds) Financial literacy: implications for retirement security and financial marketplace. Oxford University Press, Oxford, pp 17-39

Lusardi A, Mitchell OS (2011b) Financial literacy and retirement planning in the United States. J Pension Econ Financ 10(4):509-525. doi:10.1016/j.joep.2011.02.004

Lusardi A, Mitchell OS (2011c) Financial literacy around the world: an overview. J Pension Econ Financ 10(4):497-508. doi:10.1017/S1474747211000448

Lusardi A, Mitchell OS (2014) The economic importance of financial literacy: theory and evidence. J Econ Lit 52(1):5-44

Lusardi A, Tufano P (2009) Teach workers about the perils of debt. Harv Bus Rev 87(11):22-24

Lusardi A, Tufano P (2015) Debt literacy, financial experiences, and overindebtedness. J Pension Econ Financ 14(4):332-368. doi:10.1017/S1474747215000232

Lusardi A, Mitchell OS, Curto V (2010) Financial literacy among the young. J Consum Aff 44(2):358-380. doi:10.1111/j.1745-6606.2010.01173.x

Lusardi A, Michaud P-C, Mitchell OS (2013) Optimal financial knowledge and wealth inequality. NBER Working paper series no. 18669

Lusardi A, Mitchell OS, Curto V (2014) Financial literacy and financial sophistication in the older population. J Pension Econ Financ 13(4):347-366. doi:10.1017/S1474747214000031

Mandell L (2004) Financial literacy: Are we improving? Results of the 2004 national Jump\$tart survey. Jumpstart Coalition, DC, Washington

Mandell L (2008) Financial education in high school. In: Lusardi A (ed) Overcoming the saving slump: how to increase the effectiveness of inancial education and saving programs. University of Chicago Press, Chicago, pp 257-279

McDaniel L, Martin RD, Maines LA (2002) Evaluating financial reporting quality: the effects of financial expertise versus financial literacy. Acc Rev 77(4):139-167

Meier S, Sprenger C (2010) Present-biased preferences and credit card borrowing. Appl Econ Lett 2(1):193-210

Meyer S, Urban L, Ahlswede S (2015) Does a personalized feedback on investment success mitigate investment mistakes of private investors? Answers from large natural field experiment. Working paper

Monticone C (2010) How much does wealth matter in the acquisition of financial literacy? J Consum Aff 44(2):403-422

Moore D (2003) Survey of financial literacy in Washington State: attitudes, and experiences. SESRC Technical Report 03-39. doi:10.13140/2.1.4729.4722

Mottola GR (2013) In our best interest: women, financial literacy, and credit card behavior. Numeracy $6(2): 1-15$ 
Mullainathan S, Noeth M, Shoar A (2012) The market for financial advice: an audit study. NBER Working paper no. 17929

Müller S, Weber M (2010) Financial literacy and mutual fund investments: Who buys actively managed funds? Schmalenbach Bus Rev 62(2):126-153

Nicolosi G, Peng L, Zhu N (2009) Do individual investors learn from their trading experience? J Financ Mark 12(2):317-336. doi:10.1016/j.finmar.2008.07.001

OECD (2014) PISA 2012 results: students and money (Volume VI): financial literacy skills for the twenty-first century

Parker AM, de Bruin WB, Yoong J, Willis R (2012) Inappropriate confidence and retirement planning: four studies with national sample. J Behav Decis Mak 25(4):382-389. doi:10.1002/bdm.745

President's Advisory Council on Financial Literacy (PACFL) (2008) 2008 Annual report to the president. Accessed 11 Mar 2009. http://www.treas.gov/offices/domestic-finance/financial-institution/ fineducation/council/index.shtml

Remund DL (2010) Financial literacy explicated: The case for a clearer definition in an increasingly complex economy. J Consum Aff 44:276-295. doi:10.1111/j.1745-6606.2010.01169.x

Roberts MR, Whited TM (2013) Endogeneity in empirical corporate finance. In: Constantinides GM, Harris M, Stulz RM (eds) Handbook of the economics of finance, pp 493-572. doi:10.1016/B978-044-453594-8.00007-0

Rubin D (1996) Multiple imputation after 18+ years. J Am Stat Associ 91:473-489. doi:10.1080/ 01621459.1996 .10476908

Schreiner M, Clancy M, Sherraden M (2002) Saving performance in the American dream demonstration. Center for Social Development, St. Louis, Washington University

Sekita S (2011) Financial literacy and retirement planning in Japan. J Pension Econ Financ 10:637-656. doi: $10.1017 /$ S1474747211000527

Seru A, Shumway T, Stoffman N (2010) Learning by trading. Rev Financ Stud 23(2):705-739. doi:10. 1093/rfs/hhp060

Servon LJ, Kaestner R (2008) Consumer financial literacy and the impact of online banking on the financial behavior of lower-income bank customers. J Consum Aff 42(2):271-305

Shapira Z, Venezia I (2001) Patterns of behavior of professionally managed and independent investors. J Bank Financ 25(8):1573-1587

Shen CH, Lin SJ, Tang DP, Hsia YJ (2016) The relationship between financial disputes and financial literacy. Pacific Basin Financ J 36:46-65. doi:10.1016/j.pacfin.2015.11.002

Stango V, Zinman J (2009) Exponential growth bias and household finance. J Financ 64(6):2807-2849. doi:10.1111/j.1540-6261.2009.01518.x

Stolper O (2016) It takes two to tango: households' response to financial advice and the role of financial literacy. Working paper

Tang N, Peter P (2015) Financial knowledge acquisition among the young: the role of financial education, financial experience, and parents' financial experience. Financ Serv Rev 24(2):119-137

Thaler RH, Benartzi S (2004) Save More Tomorrow: using behavioral economics to increase employee saving. J Polit Econ 112(1):164-187

van Rooij MCJ, Lusardi A, Alessie RJM (2011a) Financial literacy and retirement planning in the Netherlands. J Econ Psychol 32(4):593-608. doi:10.1016/j.joep.2011.02.004

van Rooij MCJ, Lusardi A, Alessie RJM (2011b) Financial literacy and stock market participation. J Financ Econ 101(2):449-472

van Rooij MCJ, Lusardi A, Alessie RJM (2012) Financial literacy, retirement planning and household wealth. Econ J 122:449-478. doi:10.1111/j.1468-0297.2012.02501.x

Vissing-Jorgensen A (2003) Perspectives on behavioral finance: does "irrationality" disappear with wealth? Evidence from expectations and actions. NBER Macroecon Ann (18):139-194

von Gaudecker HM (2015) How does household portfolio diversification vary with financial sophistication and advice? J Financ 70(2):489-507. doi:10.1111/jofi.12231

Walstad WB, Rebeck K, MacDonald RA (2010) The effects of financial education on the financial knowledge of high school students. J Consum Aff 44(2):336-357. doi:10.1111/j.1745-6606.2010. 01172.x

Way WL, Holden KC (2009) 2009 outstanding AFCPE $^{\circledR}$ conference paper teachers' background and capacity to teach personal finance: results of a national study. J Financ Couns Plan 20(2):64-78. Retrieved from http://www.scopus.com/inward/record.url?eid=2-s2.0-79958795344\&partnerID= $40 \& m d 5=f 4 c 8 c 9491 b 598 f 9 f 29 a 63 e e a 24215 \mathrm{~cd} 2$ 
Webley P, Nyhus EK (2006) Parents' influence on children's future orientation and savings. J Econ Psychol 27:140-164

Webley P, Nyhus EK (2013) Economic socialization, saving and assets in European young adults. Econ Educ Rev 33:19-30

Willis LE (2008) Against financial literacy education. Iowa Law Rev (94):197-285

Willis LE (2011) The financial education fallacy. Am Econ Rev 101(3):429-434

Yoong JK (2011) Financial illiteracy and stock market participation: evidence from the RAND American life panel. In: Mitchell OS, Lusardi A (eds) Financial literacy: implications for retirement security and financial marketplace. Oxford University Press, Oxford, pp 76-97 